Recepción: 15 / 04 / 2017

Ciencias Económicas

Aceptación: 01 / 05 / 2017

Revisión de Literatura

Publicación: 15 / 05 / 2017

\title{
Análisis comparativo del Gasto Tributario entre Chile y Ecuador
}

\section{Comparative Analysis of Tax Expenditure between Chile and Ecuador}

\section{A análise comparativa dos gastos fiscais entre Chile e Equador}

Cynthia M. Legarda-Arreaga cynthia.legardaa@ug.edu.ec

Grace E. Tello-Caicedo" grace.telloc@ug.edu.ec

\section{Vivianna E. Vera-Almache ${ }^{\text {II }}$ viviana.veraa@ug.edu.ec}

Correspondencia: grace.telloc@ug.edu.ec

Magister en Tributación y Finanzas; Ingeniera Comercial; Docente de la Universidad de Guayaquil, Ecuador. Magister en Administración de Empresas con Mención en Recursos Humanos; Ingeniera Comercial; Docente de la Universidad de Guayaquil, Ecuador.

III. Magister en Dirección de Empresas; Diploma Superior en Diseños Pedagógicos Universitarios; Ingeniera Comercial; Docente de la Universidad de Guayaquil; Ecuador. 


\section{Resumen}

Debido a la importancia que día a día va tomando a nivel mundial los gastos tributarios o conocidos como "renuncia tributaria" que es aquello que el Estado deja de percibir en materia de impuestos con exenciones o deducciones tributarias que tiene como objetivos principales fomentar la inversión y políticas sociales. Una práctica recurrente entre los Gobiernos del mundo es eximir a determinados grupos de contribuyentes del pago de impuestos específicos. El ingreso no percibido por el Fisco se denomina Gasto Tributario (GT) y resulta equivalente a darle un apoyo por medio de una partida de gasto público a ese grupo. (Artana, 2005)

El análisis del gasto tributario parte del principio que todo impuesto debe analizarse como una unidad con dos componentes: el primero, que abarca todas las disposiciones legales que regulan la naturaleza y finalidad del objetivo, incluyendo el grupo de incidencia y la segunda, que comprende todas aquellas disposiciones que representan desvíos o excepciones a la normativa. Por lo tanto, metodológicamente se considera que hay gasto tributario cuando: (1) hay desvío de la norma; (2) hay pérdida de recaudación y (3) existe ganancia para ciertos contribuyentes. El enfoque más común es el segundo, y sólo los Estados Unidos, adicionalmente, utilizan el método de gasto-equivalente. (Villela, 2008)

Nuestro interés en poder hacer un estudio de los países Chile y Ecuador y la importancia prestada por cada país revisando sobre todo la literatura y destacando la importancia que reciben los impuestos que generan mayor recaudación como son el IVA y el Impuesto a la Renta.

Además si bien es cierto Chile y Ecuador mantienen en la actualidad la misma estructura tributaria, existen muchas diferencias lógicas en cuanto a sus economías y a la implicación de las exenciones inclusive dentro de la legislación vigente de ambos países

Para estimar el GT en Ecuador se utilizó el enfoque de determinar la recaudación que podría obtener si se gravara de acuerdo a un sistema de referencia, es decir; si es que se gravará con IVA a los productos exentos o si se quitaran las exoneraciones y deducciones especialmente en el Impuesto a la Renta. El cálculo del gasto tributario, específicamente en el IVA, no considera el efecto regresivo que pudiera tener la eliminación total de las exoneraciones en los bienes y servicios.

En cuanto a la metodología utilizada por Chile para el cálculo del Gasto Tributario, en el impuesto sobre la renta se utilizan dos metodologías de medición, las simulaciones y las estimaciones. Las 
simulaciones suponen rehacer la declaración de impuesto de cada uno de los contribuyentes, agregando a su base imponible la renta exenta o la deducción, o revirtiendo el efecto de los diferimientos, mientras tanto la parte de estimaciones basadas en datos agregados de las declaraciones o estadísticas de ingresos. En este caso, el dato básico se obtiene directamente de las declaraciones agregadas o de los ingresos tributarios, y luego se aplican los ajustes para reflejar la situación con la franquicia derogada.

La OCDE (2004) señala que la "mejor práctica" consiste en estimar los gastos tributarios por el método del ingreso renunciado, pero corrigiendo los resultados por un margen tributario equivalente, en aquellos casos en que la transferencia equivalente esté sujeta a impuestos. Además los informes de gasto tributario suelen ser utilizados también para buscar alternativas de reformas tributarias.

Palabras clave: Impuestos; recaudación tributaria; economía; sistema tributario; impuesto al valor agregado; impuesto a la renta. 


\section{Abstract}

Due to the importance that day by day is taking on a world-wide level the tributary expenses or known like "tax resignation" that is what the State stops to receive in the matter of taxes with tax exemptions or deductions whose main objectives are to encourage investment and social politics. A recurring practice among the governments of the world is to exempt certain groups of taxpayers from paying specific taxes. Income not received by the Treasury is called Tax Expenditure (GT) and is equivalent to giving support through a share of public expenditure to that group. (Artana, 2005)

The analysis of tax expenditures starts from the principle that any tax should be analyzed as a unit with two components: the first one, which covers all the legal provisions that regulate the nature and purpose of the objective, including the incidence group and the second, which includes all Those provisions that represent deviations or exceptions to the regulations. Therefore, it is methodologically considered that there is tax expenditure when: (1) there is deviation from the norm; (2) there is loss of revenue and (3) there is profit for certain taxpayers. The most common approach is the second, and only the United States, in addition, uses the expense-equivalent method. (Villela, 2008)

Our interest in being able to do a study of the countries Chile and Ecuador and the importance given by each country reviewing especially the literature and highlighting the importance that receive the taxes that generate higher collection such as VAT and Income Tax.

In addition, although Chile and Ecuador currently maintain the same tax structure, there are many logical differences in terms of their economies and the implication of exemptions even within the current legislation of both countries

To estimate the WG in Ecuador, the approach was used to determine the collection that could be obtained if it were taxed according to a reference system, that is to say, If it will be taxed with VAT on exempt products or if the exemptions and deductions are removed especially in the Income Tax. The calculation of the tax expense, specifically in the VAT, does not consider the regressive effect that could have the total elimination of the exemptions in the goods and services. 
Regarding the methodology used by Chile for the calculation of Tax Expenditure, two measurement methodologies, simulations and estimates are used in income tax. The simulations involve redoing the tax return of each of the taxpayers, adding to their tax base exempt income or deduction, or reversing the effect of deferrals, meanwhile the part of estimates based on aggregated data of statements or statistics from income. In this case, the basic data is obtained directly from the aggregate statements or from the tax revenues, and then the adjustments are applied to reflect the situation with the exempted franchise.

The OECD (2004) notes that the "best practice" is to estimate tax expenditures by means of the income foregone, but correcting the results by an equivalent tax margin, in cases where the equivalent transfer is taxable. In addition, tax expenditure reports are also used to find alternatives to tax reforms.

Key words: Taxes; tax collection; economy; tax system; value added tax; income tax. 


\section{Resumo}

Por causa da importância que a cada dia está tomando fiscal global ou despesas conhecidas como "renúncia fiscal", que é o que a precipitada Estado sobre as isenções fiscais ou deduções fiscais é principalmente destinada a promover o investimento eo políticas sociais. Uma prática recorrente entre os governos do mundo é certos grupos isentos de contribuintes do pagamento de impostos especiais de consumo. Renda perdida pelo imposto chamado de Despesa Fiscal (GT) e é equivalente a dar apoio através de uma rodada de gastos públicos para esse grupo. (Artana, 2005)

Análise dos gastos de impostos sobre o princípio de que todos os impostos deve ser analisada como uma unidade com dois componentes: o primeiro, cobrindo todas as disposições legais que regem a natureza ea finalidade do alvo, incluindo o grupo de defesa eo segundo compreendendo toda disposições que representam desvios ou exceções às regras. Portanto, metodologicamente considerase que nenhuma despesa fiscal quando: (1) não há desvio da norma; (2) sem perda de receitas e (3) não ganho para certos contribuintes. A abordagem mais comum é o segundo, e apenas os Estados Unidos, adicionalmente, usar o método de custo equivalente. (Villela, 2008)

Nosso interesse em ser capaz de fazer um estudo dos países Chile e Equador e da importância dada por cada país, especialmente de revisão de literatura e destacando a importância que recebem impostos que geram maiores receitas como o IVA e imposto de renda.

Além disso, se é verdade Chile e Equador atualmente manter a mesma estrutura de impostos, há muitas diferenças óbvias em suas economias e para o envolvimento de isenções, incluindo na legislação de ambos os países

abordagem para determinar a recolha que poderia ser obtida se tributado de acordo com um sistema de referência, que é utilizado para estimar o GT no Equador; se forem tributados com produtos ou isenções de IVA isentos e deduções especialmente no imposto de renda é removido. O cálculo das despesas fiscais, especificamente o IVA, não considera o efeito regressivo que poderia ter a total eliminação das isenções de bens e serviços.

Quanto à metodologia utilizada pelo Chile para o cálculo das despesas fiscais do imposto de renda duas metodologias de medição, simulações e estimativas são utilizadas. As simulações envolvem refazer o retorno de imposto para cada contribuinte, adicionando à sua base tributária rendimentos 
isentos ou dedução, ou reverter o efeito do diferimento, entretanto estimativas das quotas com base nas demonstrações de dados agregados ou estatísticas renda. Neste caso, os dados básicos é obtido diretamente das declarações agregados ou as receitas fiscais, em seguida, os ajustes são aplicados para refletir a situação com a franquia revogada.

OCDE (2004) observa que "melhor prática" é estimar os gastos com impostos para o método de receitas não recebidas, mas corrigindo os resultados por uma margem fiscal equivalente, nos casos em que a transferência é equivalente tributável. Além disso, relatórios de despesas de impostos são geralmente também usado para procurar por reformas tributárias alternativas.

Palavras chave: Impostos; a receita; economia; sistema tributário; imposto sobre o valor Agregado; imposto de Renda. 


\section{Introducción.}

En los últimos años la mayoría de países, particularmente los subdesarrollados, han venido implementando distintos esquemas de incentivos tributarios, como forma de promover el desarrollo de sus economías. Los principales instrumentos fiscales utilizados son las exenciones impositivas, la aplicación de tasas reducidas y el otorgamiento de créditos fiscales. Estos beneficios se han centrado principalmente en el impuesto a la renta y el impuesto al valor agregado. También se han centrado en los tributos que recaen sobre el comercio internacional. En los países desarrollados, la práctica de aplicar distintas políticas fiscales para favorecer determinadas actividades y sectores, es mucho más antigua y frecuente. Es común encontrar que estos incentivos generen gastos tributarios en niveles significativos.

Varios países de la región han empezado a realizar una estimación oficial de los gastos tributarios y en la mayoría de los casos se establece como obligatorio en la legislación, ya sea en una Ley de Responsabilidad Fiscal, en la Ley de Presupuesto o en la propia Constitución.

Como política de promoción de inversiones, los países latinoamericanos han utilizado preferentemente exenciones tributarias. Es por ello que este estudio ha puesto particular énfasis en analizar la forma de cuantificación del costo fiscal de estos incentivos, lo que usualmente se conoce como "gasto tributario". Aunque ha sido de particular complejidad en el caso de Ecuador obtener datos actualizados los gastos tributarios son estimaciones basadas en las Encuestas de Calidad de Vida (ECV) la última realizada en el año 2005-2006.

Se analizan los diferentes tipos de incentivos fiscales que se han utilizado tanto para Chile y Ecuador y se revisa la literatura que evalúa sus efectos. 
Para conocer la magnitud del ingreso no percibido, aspecto que cobra más vigencia en entornos de crisis. Si bien resulta difícil pensar que el GT sea igual al ingreso no percibido (debido a que las personas, en caso de estar gravadas, evadirían ciertos pagos), en general si es una aproximación razonable de cuánto deja de percibir el Gobierno. Además, el GT se presenta asimismo para hacer una valoración del costo-beneficio social de mantener las exoneraciones y meditar sobre la necesidad de mantenerlas o eliminarlas.

El trabajo se estructura de la siguiente forma. En un primer capítulo se establece el marco conceptual-metodológico sobre el tema del gasto tributario. Luego, el capítulo 2 desarrolla una breve reseña sobre la normativa de ambos países estudiados en torno del GT. En los capítulos subsecuentes se presentan los cálculos correspondientes para los distintos tipos de impuestos primero el caso de Chile y posteriormente Ecuador. Y las comparaciones con otros países de América latina. El documento cierra con algunas consideraciones finales sobre el tema que deben ser tomadas en cuenta al momento de analizar las cifras.

\section{Elementos Conceptuales}

\section{Concepto de Gasto Tributario}

Se define como "gasto tributario" al "monto de ingresos que un Estado deja de percibir al otorgar un tratamiento impositivo que se aparta del establecido con carácter general en la legislación tributaria y que tiene por objetivo beneficiar, promover o fomentar a determinadas actividades, sector, rama, región o grupos de contribuyentes. Por lo general, se traduce en el otorgamiento de 
exenciones o deducciones tributarias, alícuotas diferenciales, diferimientos y amortizaciones aceleradas, entre otros mecanismos". ${ }^{1}$

Una segunda acepción utilizada para la realización de este trabajo, señala que los gastos tributarios son definidos como la "recaudación que el fisco deja de percibir en virtud de la aplicación de concesiones o regímenes impositivos especiales, y constituye una de las herramientas de que disponen los gobiernos para ejecutar sus políticas públicas, con el objetivo de favorecer o estimular a determinados sectores, actividades, regiones o agentes de la economía. También se le llama "renuncia tributaria", ya que el fisco puede desistir parcial o en su totalidad de aplicar el régimen impositivo general, otorgando mayor importancia a la consecución de un objetivo superior de política económica y social. ${ }^{2}$

\section{Condiciones adicionales para considerar a un "gasto tributario"}

En muchos países se añaden determinados requisitos para considerar a un gasto tributario como tal. Pese a que no existe consenso sobre este punto, en el informe de la OCDE (1996) se hace referencia a un conjunto de requisitos exigidos por algunos países, tales $\operatorname{como}^{3}$ :

Las concesiones tributarias deben beneficiar a una industria, actividad o clase de contribuyentes en particular;

Deben servir a un propósito particular (diferente de la operación eficiente del sistema), que sea fácilmente identificable con un objetivo que puede ser llevado a cabo en forma alternativa con otros instrumentos;

\footnotetext{
${ }^{1}$ Dirección de Presupuestos del Gobierno de Chile. "Medición y Evaluación del Gasto Tributario. Informe del Comité Asesor para estudiar y proponer adecuaciones al Informe Anual de Gastos Tributarios". Septiembre de 2012. P. 9.

${ }^{2}$ Villela, Luiz; Lemgruber, Andrea y Jorrat, Michael. "Los presupuestos de gastos tributarios: Conceptos y desafíos de implementación”. En: Documento de Trabajo BID $N^{\circ} I D B-W P-131$. Banco Interamericano de Desarrollo. Diciembre de 2009. P. 2.

${ }^{3}$ Ibid. P.6.
} 
El impuesto en cuestión tiene que ser lo bastante amplio como para que haya un impuesto de referencia adecuado contra el cual medir el valor de la concesión;

Tiene que ser administrativamente factible cambiar el sistema tributario para eliminar el gasto tributario, y en el sistema tributario no debe haber otras disposiciones que compensen con holgura los beneficios del gasto tributario.

\section{Modalidades de Gasto Tributario}

Los gastos tributarios adoptan diversas formas o modalidades, entre las cuales se pueden mencionar ${ }^{4}:$

Exenciones: Ingresos o transacciones que se excluyen de las bases imponibles. En las normas legales se las encuentra bajo distintas denominaciones, tales como exenciones, exoneraciones, hechos no gravados, etc.

Deducciones: Cantidades que se permite rebajar de las bases imponibles.

Créditos: Cantidades que se permite rebajar de los impuestos.

Tasas reducidas preferenciales: Alícuotas de impuestos inferiores a las de aplicación general.

Diferimientos: Postergación o rezago en el pago de un impuesto.

Regímenes especiales: determinación de la base imponible o del pago del impuesto mediante fórmulas distintas a la de aplicación general.

\footnotetext{
${ }^{4}$ Jorrat, Michael. “Gastos Tributarios y Evasión Tributaria en Chile. Evaluación y Propuestas”. Mayo 2012. P.5.
} 


\section{Objetivos de los Gastos Tributarios}

Los gastos tributarios persiguen diferentes objetivos, entre los cuales se pueden mencionar los siguientes ${ }^{5}$ :

\section{Mejorar la progresividad del sistema tributario}

Existen gastos tributarios que se establecen para reducir la tributación de las personas de menores ingresos, a fin de mejorar la progresividad del sistema tributario. Estas concesiones son frecuentes en el IVA, cuando se aplican exenciones a la canasta básica o, en general, a aquellos bienes cuyo consumo representa una parte mayor del ingreso de las personas pobres que de las personas de mayores recursos.

\section{Otorgar una mayor eficiencia a la estructura tributaria}

Existe otro tipo de gastos tributarios que buscan reducir las distorsiones propias del impuesto. Estos son más frecuentes en los Impuestos a la Renta de las personas físicas, donde se busca reducir los desincentivos que provoca sobre la inversión, el ahorro o el empleo.

En el impuesto a las empresas, se consideran las moratorias fiscales, que eximen a determinadas empresas del pago del impuesto por un período específico; los esquemas de depreciación acelerada, que permiten transformar las inversiones en gasto en un período inferior a la vida útil económica de los activos; la reducción de las tasas impositivas sobre las utilidades devengadas, o en algunos casos sobre las utilidades reinvertidas; y los créditos tributarios a la inversión.

\footnotetext{
${ }^{5}$ Ibid. P.6.
} 
En los impuestos sobre las rentas personales, los incentivos están orientados a estimular el ahorro, a través de mecanismos como: la deducción de la base imponible de los montos ahorrados en ciertos instrumentos financieros; la exención a los intereses financieros y otras rentas de capitales mobiliarios; la aplicación de tasas reducidas sobre algunas rentas financieras; o la aplicación de créditos proporcionales al ahorro neto efectuado en el período tributario.

\section{Estimular actividades o consumo de bienes meritorios}

Otros gastos tributarios buscan incentivar el desarrollo de actividades o el consumo de determinados bienes o servicios que tienen el carácter de "meritorios", es decir, que independientemente de su impacto sobre la progresividad, se considera que tienen efectos económicos o sociales positivos. Este es el caso de los gastos tributarios que favorecen a la educación, la salud, la vivienda, las actividades deportivas, los libros o las actividades culturales.

Este tipo de gastos tributarios se encuentran frecuentemente en el IVA, en donde a muchos de los productos o servicios antes mencionados se les exime del impuesto o se les aplica una tasa reducida. También están en el Impuesto a la Renta, por ejemplo, en las exenciones a las entidades sin fines de lucro o las deducciones por gastos en educación o salud.

\section{Promover el desarrollo regional o sectorial}

Otro de los objetivos, es incentivar el desarrollo de determinadas zonas geográficas o industrias específicas. Por ejemplo, las denominadas zonas francas, generalmente establecidas en territorios extremos, en donde se establecen incentivos como la exoneración de IVA e Impuesto a la Renta por un plazo determinado de tiempo. 
También, muchos países establecen reducciones tributarias para estimular el desarrollo de actividades económicas consideradas estratégicas. Dentro de esta categoría, se consideran los incentivos para atraer inversión extranjera directa, los que a su vez pueden estar asociados a las inversiones realizadas en una zona geográfica o industria particular.

\section{Reducir los costos de cumplimiento}

Dentro de esta categoría, se incluyen los regímenes simplificados para pequeños contribuyentes, que se aplican para evitar que éstos deban llevar registros contables complejos, o también las exenciones para rentas ocasionales o de bajo monto, que se establecen para liberar a las personas de la obligación de hacer declaraciones de impuestos. Estas concesiones deben ser consideradas gastos tributarios cuando, además de reducir costos de cumplimiento, significan un menor pago de impuestos respecto del que se aplicaría en el régimen general.

\section{Fomentar el cumplimiento}

Se refiere a los estímulos incorporados en los sistemas tributarios para el pago de impuestos. En algunos países se permite deducir del Impuesto a la Renta los gastos de vida, siempre que el contribuyente los acredite con las respectivas facturas. En otros, se aplica una tasa reducida de IVA cuando los pagos se realizan con medios electrónicos, lo que permite a la administración tributaria un mejor control del cumplimiento.

\section{Desgravar pagos obligatorios}

Finalmente, es frecuente que se exima de impuestos a aquellas transacciones que las personas deben realizar por mandato legal. Por ejemplo, en varios países se exime de IVA a las comisiones que cobran los agentes privados por la administración de los fondos de pensiones 
financiados con aportes obligatorios de los trabajadores; o a las primas de los seguros obligatorios que cubren riesgos de accidentes de tránsito.

\section{Medición de los Gastos Tributarios}

La medición de los gastos tributarios no es un proceso sencillo, ya que requiere definir un impuesto de referencia (benchmark) sobre el cual se comparan las disposiciones legales de cada impuesto. 6

\section{Enfoques de la medición}

Craig y Allan (2001) señala que existen tres los enfoques utilizados para definir el impuesto de referencia necesario para calcular los gastos tributarios:

Enfoque conceptual: Se vincula el impuesto de referencia con una "estructura tributaria normal", no necesariamente relacionado con las definiciones legales del impuesto. Por lo tanto, cada vez que el impuesto real deja de aplicarse sobre esta renta conceptual, o se aplica sobre una cantidad menor, aparece un gasto tributario. En el impuesto a la renta, los países que utilizan este enfoque, se basan en el concepto renta de Haig-Simons, según el cual la renta corresponde al consumo realizado en un período más la variación experimentada por el valor del patrimonio entre el inicio y el término de ese período. Por lo tanto, cada vez que la legislación tributaria reduce de la base imponible algún componente de la renta Haig-Simons, surge un gasto tributario. En el IVA se utiliza generalmente el consumo con una base amplia territorial.

${ }^{6}$ Comité Asesor para estudiar y proponer adecuaciones al Informe anual de Gastos Tributarios. "Medición y Evaluación del Gasto Tributario". Septiembre de 2012. Santiago de Chile. Pp. 35-37. 
Enfoque legal: Se utiliza la legislación tributaria vigente como base para definir el impuesto de referencia y para identificar los gastos tributarios. Por lo tanto, los gastos tributarios son aquellas excepciones expresamente mencionadas en la Ley.

Enfoque del subsidio análogo: identifica como gastos tributarios solo aquellas concesiones tributarias que son claramente equivalentes a un subsidio directo, lo que en la práctica implica una identificación de gastos tributarios muy similar a la del enfoque legal.

\section{Impuestos Considerados para la medición del Gasto Tributario}

Para la medición del gasto tributario de ambos países se utilizarán los impuestos a la Renta y el IVA, ya que son los principales impuestos en la estructura tributaria de ambos países (Ecuador y Chile).

Una vez que se define el "impuesto de referencia", se deben definir otros elementos de los impuestos como, por ejemplo, la estructura de la tasa del impuesto de referencia, la unidad de tributación, el período de tributación y las deducciones aceptadas que se consideran parte de la base y las que son parte de la excepción. ${ }^{7}$

Las prácticas más comunes utilizadas por los distintos países son las siguientes:

En el Impuesto a la Renta:

1. Estructura de tasas: se consideraría que la estructura progresiva de tasas contenida en la ley forma parte del impuesto de referencia. Es decir, que el tramo exento habitual en las escalas de tasas no da origen a un gasto tributario, como tampoco las tasas marginales inferiores a la máxima.

\footnotetext{
${ }^{7}$ Ibid. P.37.
} 
2. Unidad de tributación: en general, se toman como parte del impuesto de referencia las unidades de tributación aceptadas en la ley (por ejemplo, declaración individual, matrimonial o familiar).

3. Período de tributación: se considera que los períodos de tributación definidos en la ley son parte de la referencia.

4. Deducciones: Deducciones de gastos necesarios para producir la renta -lo cual es consistente con la definición de renta de Haig-Simons- así como las deducciones de pagos obligatorios.

5. Otros: Se incluye como parte de la referencia, las convenciones contables para determinar la renta, las disposiciones que procuran facilitar la administración del impuesto, las que persiguen evitar la doble tributación, las relacionadas con la tributación internacional y la deducción de pérdidas de períodos anteriores.

En el IVA:

1. Tasas: La tasa legal de aplicación general. En consecuencia, las tasas reducidas darán origen a gastos tributarios y las sobretasas producirán gastos tributarios negativos.

2. Remanentes: El tratamiento legal de los remanentes es parte de la referencia. No obstante, en el caso de que haya un sector o grupo de contribuyentes privilegiado con una devolución de remanentes, dicho tratamiento debe constituir un gasto tributario.

3. Devoluciones: Las devoluciones del IVA a los exportadores como parte del impuesto de referencia. Esto es consistente con un IVA en destino con base consumo. 
Cynthia M. Legarda-Arreaga; Grace E. Tello-Caicedo; Viviana E. Vera-Almache

\section{Método de cálculo o estimación del Gasto Tributario}

Además de medir el impuesto de referencia (benchmark), es necesario definir el método de estimación del costo del gasto tributario para el fisco. ${ }^{8}$

Existen tres métodos de cálculo utilizados para estimar los gastos tributarios:

Método del ingreso renunciado (perdido): Mide la pérdida de ingresos que se produce después de introducir un gasto tributario. Supone que no hay cambio alguno de comportamiento en los contribuyentes, es decir, que su comportamiento es el mismo que exhibían antes de la aplicación del gasto tributario. Este método es conocido también como medición ex post.

Método del ingreso ganado: Intenta estimar la recaudación adicional que es posible obtener con la derogación de un gasto tributario. A diferencia del método anterior, en éste -denominado también medición ex ante- se toman en cuenta los cambios de comportamiento de los contribuyentes.

Método del gasto directo equivalente: Estima el subsidio o la transferencia que dejaría a los contribuyentes con un ingreso neto de impuestos similar al que obtienen con la existencia del gasto tributario.

\footnotetext{
${ }^{8}$ Ibid. P.38.
} 


\section{Evaluación de los Gastos Tributarios}

\section{Ventajas y Desventajas de los Gastos Tributarios}

Los gastos tributarios se consideran como un instrumento más dentro de los distintos instrumentos de política pública de que disponen los gobiernos, tales como la acción presupuestaria directa o la acción reguladora sobre determinadas actividades.

Sin embargo, como instrumento de política pública requiere de una evaluación de su aplicación, de sus ventajas y desventajas.

En relación a las ventajas, algunos autores (Swift et al (2004)), mencionan los siguientes aspectos positivos de los gastos tributarios ${ }^{9}$ :

Incentivan la participación del sector privado en programas económicos y sociales donde el gobierno juega un rol principal.

Promueven la toma de decisiones privadas por sobre la toma de decisiones del gobierno.

Reducen la necesidad de supervisión estatal de los gastos directos equivalentes.

En este último punto, es necesario precisar que si bien la aplicación de un gasto tributario elimina la necesidad de supervisión estatal que requiere todo gasto directo, al mismo tiempo surge la necesidad de supervisar y controlar el correcto uso del beneficio tributario, así como de los espacios para fraudes tributarios que eventualmente pueden aparecer.

En relación a las desventajas de los gastos tributarios, un artículo escrito por El Profesor Surrey, en 1970, titulado "Tax Incentives as a Device for Implementing Government Policy: A

\footnotetext{
${ }^{9}$ Ibid. P.9
} 
comparison with Direct Government Expenditures", identifica cinco desventajas de los incentivos tributarios en relación con los subsidios directos, al momento de implementar una política pública ${ }^{10}$ :

Los incentivos tributarios son regresivos por naturaleza: Los incentivos tributarios lógicamente benefician a quienes pagan impuestos. Con un impuesto a la renta progresivo, en el que se basa esta aseveración, los grupos de bajos recursos no están afectos y, por ende, no se benefician de los gastos tributarios. No obstante, se debe matizar esta afirmación considerando que en el IVA y otros impuestos, la aplicación de franquicias puede contribuir a mejorar la progresividad del sistema tributario. Sin embargo, también pueden contribuir a fomentar la evasión.

Los incentivos tributarios crean ganancias inesperadas: Muchos gastos tributarios pueden crear incentivos para que las personas hagan aquello que habrían hecho de todas formas, por lo que finalmente el estímulo se transforma en un regalo inesperado o una renta para el beneficiario. Es decir, para incentivar a uno se asume el costo de varios.

Los incentivos tributarios son más difíciles de administrar y controlar: La Administración Tributaria no tiene experiencia en administrar y controlar programas de gasto público. Sin embargo, cuando se establece un gasto tributario se ve obligada a cumplir esta función.

Los incentivos tributarios distorsionan las decisiones de los mercados: En la medida en que un gasto tributario favorece a un sector específico de la economía, producirá un desvío de recursos no deseado hacia el sector favorecido. En todo caso, esto no es necesariamente una desventaja en aquellos casos en que el gasto tributario busca corregir una distorsión causada previamente por el impuesto, como es el caso de los estímulos a la inversión y el ahorro.

${ }^{10}$ Ibid. P.8 


\section{Los incentivos tributarios obligan a mantener tasas más altas de las que serían necesarias}

sin dichos incentivos. Para recaudar una cantidad determinada, se requerirán tasas más altas si es que una parte de la recaudación potencial se pierde por causa de la aplicación de gastos tributarios. Tasas más altas a su vez generan mayores distorsiones en las decisiones de los contribuyentes.

Otros elementos necesarios que se deben considerar al momento de contrastarlos y analizar sus ventajas y desventajas con otras herramientas de política pública son los siguientes:

Focalización: Desde el punto de vista de los beneficiarios, las franquicias tributarias tienen un acceso más simple que el subsidio directo, pues operan de manera relativamente automática, mientras que un programa de subsidios requiere de un sistema de postulación y selección de beneficiarios. Por el contrario, desde el punto de vista del Estado, al ser automáticas, las franquicias tributarias son menos focalizadas, beneficiando tanto al grupo objetivo como a cualquier otro que cumpla o simule cumplir la normativa legal.

Inequidad horizontal: Los gastos tributarios suelen crear inequidad en un sentido horizontal, puesto que no todas las personas tienen las mismas preferencias o necesidades de consumo. Así por ejemplo, cuando se establecen exenciones al IVA, ya sea para mejorar la progresividad o para estimular el consumo de bienes meritorios, se reduce proporcionalmente más la carga tributaria de las familias que manifiestan una preferencia por los bienes que se dejan exentos, en desmedro de otras familias con igual nivel de ingresos pero que privilegian el consumo de otros bienes no favorecidos.

Estímulos a la evasión y la elusión: La aplicación de gastos tributarios hacen más compleja la estructura tributaria, lo que incrementa la evasión y elusión por diversas razones, entre las cuales se mencionan: a) La incertidumbre que producen en cuanto a la correcta interpretación de las 
normas legales; b) la merma en la capacidad de fiscalización de la administración tributaria, ya que cada auditoría demanda más tiempo cuando la normativa es compleja; c) la mayor dificultad que imponen a los contribuyentes para cumplir con sus obligaciones tributarias, lo que los lleva a incumplir parte de ellas ya sea por desconocimiento o para compensar los costos que el sistema les impone; y por último, d) las mayores oportunidades para manipular el sistema tributario, es decir, existen mayores espacios de evasión y elusión que se abren a medida que aumenta la complejidad de la normativa tributaria.

Aumento de los costos de cumplimiento tributario: En la medida que existan mayores incentivos tributarios mayores son los costos en tiempo y dinero que los contribuyentes deben incurrir para cumplir con sus obligaciones tributarias. No siempre estos costos recaen en los beneficiarios del incentivo. Por ejemplo, las exenciones de IVA benefician a los consumidores finales, pero los mayores costos de cumplimiento derivados de los registros especiales para la contabilización de ventas exentas y créditos de IVA recaen sobre los vendedores. En el caso del Impuesto a la Renta, muchas franquicias requieren para su control, contar con información que debe ser provista por terceras personas.

Un trabajo realizado por Tokman et al. (2006) propone la evaluación permanente de los gastos tributarios de la estructura tributaria, para lo cual se sugiere ocho dimensiones en las cuales es relevante contrastar el desempeño de un gasto tributario frente a un subsidio directo. Estas dimensiones se muestran en la siguiente tabla: 
Análisis comparativo del Gasto Tributario entre Chile y Ecuador

\begin{tabular}{|c|c|c|}
\hline Dimensión & Excepciones tribut arias & Subsidios directos \\
\hline Accesibilidad de beneficiarios & Simple por su autom aticidad. & $\begin{array}{l}\text { Más compleja, pues requiere } \\
\text { selección. }\end{array}$ \\
\hline Costos administrativos & $\begin{array}{l}\text { Bajos para la franquicia, pero } \\
\text { altos para el sistema tributario } \\
\text { como untodo, por complejizarlo. }\end{array}$ & $\begin{array}{l}\text { De nivel medio, por la necesidad } \\
\text { de un sistema de selección y } \\
\text { asignación. }\end{array}$ \\
\hline Posibles malos usos & $\begin{array}{l}\text { Espacios para elusión, evasión y la } \\
\text { búsqueda de rentas. }\end{array}$ & $\begin{array}{l}\text { Espacios para arbitrariedades y } \\
\text { captura del ente asignador. }\end{array}$ \\
\hline Flexibilidad & $\begin{array}{l}\text { Opera con leyes permanentes, } \\
\text { generando estabilidad, pero } \\
\text { también inercia. }\end{array}$ & $\begin{array}{l}\text { Opera con presupuestos, } \\
\text { evaluaciones y reasignaciones } \\
\text { periódicas. }\end{array}$ \\
\hline $\begin{array}{l}\text { Transparencia y rendición de } \\
\text { cuentas }\end{array}$ & $\begin{array}{l}\text { Su automaticidad no considera } \\
\text { formas de control ni rendición de } \\
\text { cuentas. }\end{array}$ & $\begin{array}{l}\text { Al ser un gasto gubernamental, } \\
\text { debe ser aprobado por el } \\
\text { Congreso. }\end{array}$ \\
\hline Control de gastos & $\begin{array}{l}\text { Gastos determinados ex post, } \\
\text { inciertos y no acotables, } \\
\text { pudiendo generar desequilibrios } \\
\text { fiscales. }\end{array}$ & $\begin{array}{l}\text { Gasto programado y controlado, } \\
\text { acotado a Ley de Presupuestos. }\end{array}$ \\
\hline Efectividad & $\begin{array}{l}\text { No se puede asegurar } \\
\text { adicionalidad en la acción que se } \\
\text { desea fomentar. Se financian } \\
\text { casos inframarginales. }\end{array}$ & $\begin{array}{l}\text { Riesgo de desplazamiento del } \\
\text { accionar privado y dificultad para } \\
\text { asegurar adicionalidad. }\end{array}$ \\
\hline Equidad & $\begin{array}{l}\text { Sólo acceden quienes tributan, y } \\
\text { más intensivamente quienes } \\
\text { tienen mayores ingresos. }\end{array}$ & $\begin{array}{l}\text { La discrecionalidad puede facilitar } \\
\text { un acceso más equitativo, } \\
\text { posibilitando la focalización de } \\
\text { beneficiarios. }\end{array}$ \\
\hline
\end{tabular}

\section{Bases Normativas de los Gastos Tributarios en Chile y Ecuador.}

En Chile no existe una obligación legal de medir ni de elaborar un presupuesto de gastos tributarios, pero a partir de una interpretación del artículo 19, numeral 22, de la Constitución, que señala que: "En el caso de las franquicias o beneficios indirectos, la estimación del costo de éstos deberá incluirse anualmente en la Ley de Presupuestos"; se establece una obligatoriedad indirecta. ${ }^{11}$

En el caso de Ecuador el 15 de septiembre de 2010, el Presidente Constitucional de la República remitió a la Asamblea Nacional, el proyecto de Código Orgánico de Planificación y Finanzas Públicas, cuyo artículo 103 estipula lo siguiente: “Art. 103.- Renuncia de ingresos por gasto tributario.- Se entiende por gasto tributario los recursos que el Estado, en todos los niveles de

${ }^{11}$ Jorrat, Michael. Op. Cit. P. 19. 
gobierno, deja de percibir debido a la deducción, exención, entre otros mecanismos, de tributos directos o indirectos establecidos en la normativa correspondiente.

Para el gasto tributario de los ingresos nacionales, la administración tributaria nacional estimará y entregará al ente rector de las finanzas públicas, la cuantificación del mismo y constituirá un anexo de la proforma del Presupuesto General del Estado.

Para el gasto tributario de los ingresos de los gobiernos autónomos descentralizados, la unidad encargada de la administración tributaria de cada gobierno autónomo, lo cuantificará y anexará a la proforma presupuestaria correspondiente." En virtud de esta disposición, la Administración Tributaria realiza la estimación de los gastos tributarios con la finalidad de contribuir a transparentar las finanzas públicas.

La definición del gasto tributario en el Ecuador se realizó en base a la Ley Orgánica de Régimen Tributario Interno (LORTI), el Reglamento de la Ley de Régimen Tributario Interno. Además la Ley de Anciano, Ley de Turismo, Ley de Zonas Francas y Ley de Promoción y Garantía de Inversiones.

La base correspondiente al Impuesto a la Renta se encuentra estructurada principalmente en los artículos 9, 10, 11, 13, 36 y 41 de la LORTI, correspondientes a exenciones, deducciones, amortización, pagos al exterior, y reinversión respectivamente.

En el caso del Impuesto al Valor Agregado, se utilizaron los artículos 54 y 55, 56, 67, 73 y 74 de la LORTI, los cuales establecen como exentos o no sujetos del pago de IVA distintos bienes y servicios. Por otro lado, también se incluye el Decreto Presidencial 1232, en donde se incluyen varios productos con tarifa $0 \%$. 
Una característica distintiva es la presentación del gasto tributario en el IVA según deciles de ingresos y al mismo tiempo por tipos de bienes y servicios. No obstante, en este país se consideran menos modalidades de gastos tributarios en comparación con Chile, ya que sólo se estima la pérdida de recaudación debido a la existencia de productos exentos en el IVA y a exoneraciones y deducciones especiales en el impuesto a la Renta

\section{Análisis del Gasto Tributario en Chile}

A partir de la interpretación del artículo 19, $\mathrm{N}^{\circ} 22$ de la CT Política de Chile, desde el año 2002, el Servicio de Impuestos Internos (SII) efectúa la estimación. Estas estimaciones son incorporadas en el Informe de Finanzas Públicas que elabora la Dirección de Presupuestos para la elaboración del Presupuesto de la Nación.

Esta medición se realiza anualmente, para los impuestos de IVA e Impuesto a la Renta.

El SII define gasto tributario como un "tratamiento tributario que se desvía del tratamiento normal y que con ello se favorece, promueve o estimula a un sector o agente de la economía". ${ }^{12}$

A partir de esa definición, en la identificación de los gastos tributarios se usa el enfoque conceptual. El método de cálculo o estimación es el "ingreso renunciado", pero también aplica el supuesto de "gasto total constante", el cual asume que la eventual derogación de una franquicia produce un menor ingreso disponible para los contribuyentes, con lo cual disminuye también su consumo afectable con IVA. Así, en la medición se contabiliza el IVA que se dejaría de recaudar

\footnotetext{
${ }^{12}$ Ibid
} 
con la eventual derogación de cada franquicia. Por tanto, existe una combinación entre el método de "ingreso renunciado" y el "ingreso ganado". 13

El informe anual que elabora el SII, muestra la ejecución del gasto tributario del año anterior, la proyección para el año en curso y la estimación para el año siguiente.

Además, el SII clasifica los gastos tributarios de acuerdo a dos criterios: 1) El sector u objetivo beneficiado y 2) a las partidas más relevantes, todo lo cual es publicado en el "Informe de Finanzas Públicas” que cada año elabora la Dirección de Presupuestos.

Inicialmente, se analizará la evolución de los gastos tributarios para los impuestos de referencia (Impuesto a la Renta e IVA) entre el período 2001 y 2011. Posteriormente se realiza un análisis de los datos correspondientes al año 2012.

\section{Evolución del Gasto Tributario período 2001-2011}

En el período comprendido entre 2001 y 2011, los gastos tributarios han aumentado significativamente, como lo muestra el gráfico que se presenta a continuación:

\footnotetext{
${ }^{13}$ Ibid.

${ }^{14}$ Ibid. P. 21.
} 


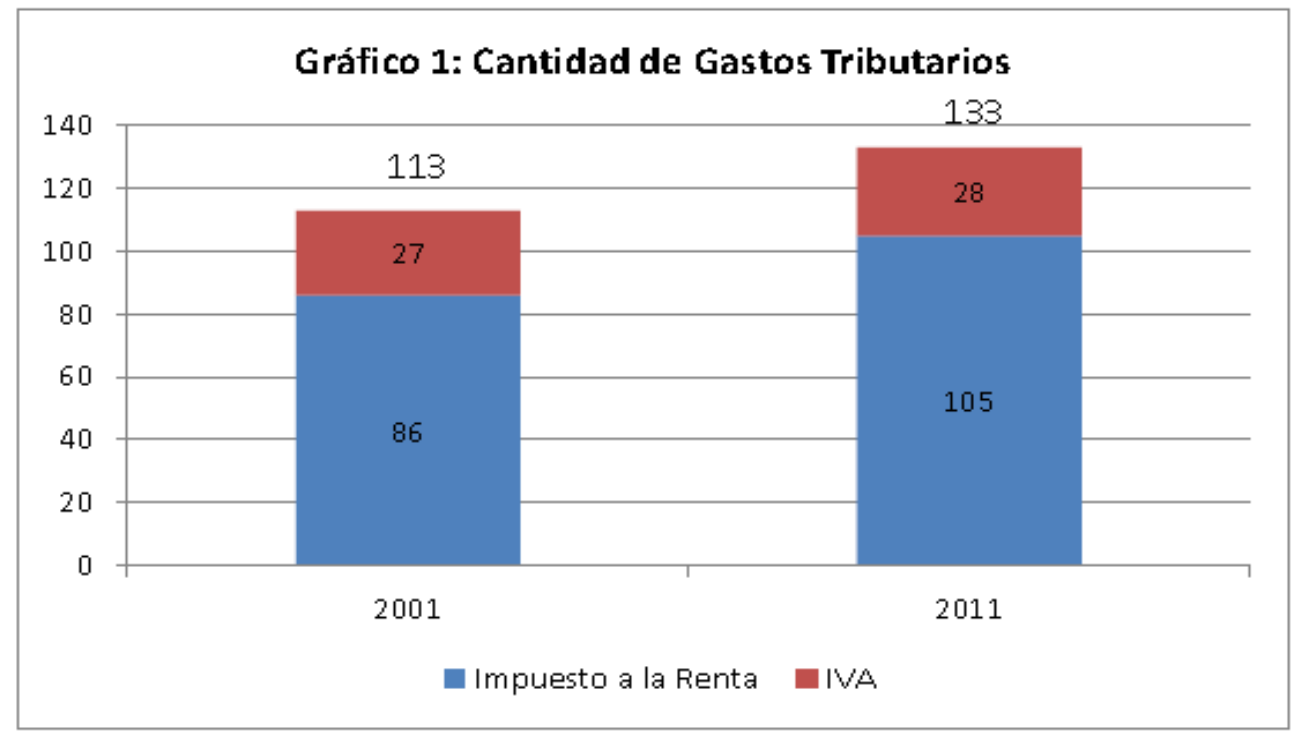

Fuente: Elaborado por Michel Jorrat, en base a informes anuales de gastos tributarios del SII.

De acuerdo al gráfico, en el año 2001, se contabilizó un total de 113 gastos tributarios, 27 en el IVA y 86 en el impuesto a la renta. En el año 2011, se incrementan a 133, que representa un aumento de $18 \%$.

Durante el período, la mayor parte de los nuevos gastos tributarios corresponden al impuesto a la renta. Entre cabe mencionar la creación de los regímenes simplificados, la deducción por intereses de créditos hipotecarios; la exención a las ganancias de capital de riesgo; la zona franca de Tocopilla (localidad del norte del país); las leyes de donaciones para fines sociales, partidos políticos y catástrofes; y el incentivo a la investigación y desarrollo.

A continuación se presenta un gráfico que muestra la magnitud de los gastos tributarios (costo fiscal del gasto tributario como porcentaje del PIB) para los impuestos de referencia (Impuesto a la Renta e IVA), durante el año 2002 y 2011: 
Cynthia M. Legarda-Arreaga; Grace E. Tello-Caicedo; Viviana E. Vera-Almache

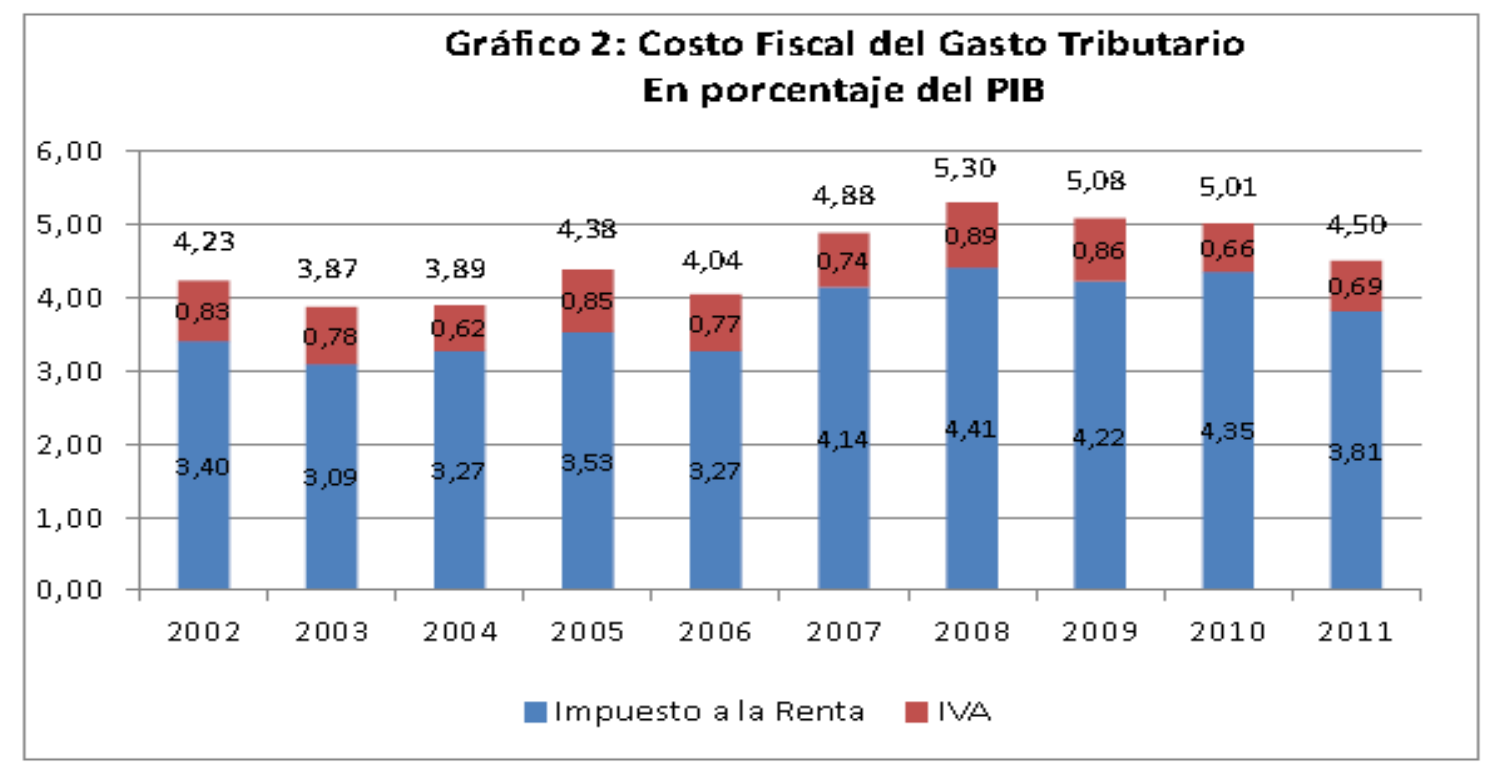

Fuente: Elaborado por Michel Jorrat, en base a informes anuales de gastos tributarios del SII.

El gráfico anterior muestra que el costo fiscal ha variado entre 3,9\% del PIB (2003) y 5,3\% del PIB (2008). Los gastos tributarios del impuesto a la renta tienen una mayor importancia relativa, con un costo fiscal que ha variado entre $3,1 \%$ y $4,41 \%$ del PIB. Por su parte, el costo fiscal de los gastos tributarios del IVA, ha tenido una variación entre $0,62 \%$ y $0,89 \%$ del PIB.

\section{Análisis Gasto Tributario en año 2012}

La tabla anterior muestra el gasto tributario total para el año 2012 en el Impuesto a la Renta e IVA, en millones de pesos, y como porcentaje del $\mathrm{PIB}^{15}$ :

\footnotetext{
${ }^{15}$ Comité Asesor para estudiar y proponer adecuaciones al Informe anual de Gastos Tributarios. Op. Cit. Pp.45 y 46.
} 
Análisis comparativo del Gasto Tributario entre Chile y Ecuador

\begin{tabular}{|c|c|c|}
\hline & Millones de $\$$ & $\%$ del PIB \\
\hline Impuesto a la renta & 3.609 .951 & $2,87 \%$ \\
\hline Regímenes especiales & 54.046 & $0,04 \%$ \\
\hline Exenciones & 267.038 & $0,21 \%$ \\
\hline Deducciones & 369.280 & 0,2986 \\
\hline Créditos al impuesto & 299.818 & 0,249 \\
\hline Diferimientos del impuesto & 2.614 .217 & $2,08 \%$ \\
\hline Tasas reducidas & 5.551 & $0,00 \%$ \\
\hline IVA & 868.538 & $0,69 \%$ \\
\hline $\begin{array}{l}\text { Exenciones yhechos no } \\
\text { gravados }\end{array}$ & 465.275 & 0,3796 \\
\hline Créditos & 403.263 & $0,32 \%$ \\
\hline Diferimientos del impuesto & o & 0,009 \\
\hline TOTAL & 4.478 .490 & $3,57 \%$ \\
\hline
\end{tabular}

Fuente: Servicio de Impuestos Internos

En la tabla siguiente se muestra el Gasto Tributario por Sector u Objetivo beneficiado (Millones de \$1\% PIB):

\begin{tabular}{|l|c|c|c|}
\hline Sector/objetivo & Millones de $\$$ & $\%$ del PIB & $\%$ del total \\
\hline Ahorro-inversión & 2.759 .597 & $2,19 \%$ & $61,62 \%$ \\
\hline Inmobiliario & 509.859 & $0,41 \%$ & $11,38 \%$ \\
\hline Salud & 393.947 & $0,31 \%$ & $8,80 \%$ \\
\hline Educación & 304.523 & $0,24 \%$ & $6,80 \%$ \\
\hline Resto de sectores & 185.189 & $0,15 \%$ & $4,14 \%$ \\
\hline Fomento ala MYPE & 176.880 & $0,14 \%$ & $3,95 \%$ \\
\hline Regional & 83.763 & $0,07 \%$ & $1,87 \%$ \\
\hline Transporte & 45.560 & $0,04 \%$ & $1,02 \%$ \\
\hline Seguros & 24.231 & $0,02 \%$ & $0,54 \%$ \\
\hline Exportaciones & 2.880 & $0,00 \%$ & $0,06 \%$ \\
\hline No asignado & -7.939 & $-0,01 \%$ & $-0,18 \%$ \\
\hline ToTAL & $\mathbf{4 . 4 7 8 . 4 9 0}$ & $3,57 \%$ & $\mathbf{1 0 0 , 0 0 \%}$ \\
\hline
\end{tabular}

Fuente: Servicio de Impuestos Internos 
De acuerdo a la información de la tabla, como se mencionó anteriormente, para efectos de medición se consideran gastos tributarios todas las desviaciones respecto del tratamiento tributario normal y que con ello favorezcan, promuevan o estimulen a un sector o agente de la economía. Esta medición se realiza tanto para el impuesto a la renta como para el IVA.

\section{Impuesto a la Renta}

Para definir el impuesto de referencia (benchmark) respecto del cual se realiza la comparación o se define la desviación, en el Impuesto a la Renta, el SII ha definido como norma, el que considere las siguientes características:

Se utiliza la definición de renta de Haig-Simons: Se considera como la base imponible del impuesto el ingreso o renta de las personas, que de acuerdo a esta definición, equivale a la variación que experimenta su patrimonio entre dos momentos del tiempo más el consumo durante ese mismo período.

Dentro de esta categoría se encuentran los incentivos al ahorro tales como los establecidos en el artículo 57 bis (Ley de Impuesto a la Renta) la deducción de las cotizaciones previsionales de la base del impuesto de segunda categoría y la exención de impuestos que beneficia a los ahorros previsionales administrados por las AFP, entre otros, son tratados como gastos tributarios

Los sujetos del impuesto son las personas naturales: En este caso, los impuestos que pagan las personas jurídicas son a cuenta de los impuestos personales.

Las tasas y tramos de renta corresponden a las vigentes y se consideran parte de la norma.Los regímenes para pequeños contribuyentes y de contabilidad simplificada se consideran parte de la norma. 


\section{Impuesto al Valor Agregado (IVA)}

El SII define la norma de referencia (benchmark) para el impuesto al valor agregado en base al supuesto que el IVA es un impuesto al consumo y, por tanto, grava la totalidad de las ventas e importaciones de bienes y servicios con una tasa única y pareja.

Adicionalmente, se considera la tasa cero de IVA a las exportaciones como parte de la norma, pues su objetivo es evitar la doble tributación de las exportaciones más que favorecer a un sector particular. Por lo tanto, no constituyen un gasto tributario.

Como ya se ha señalado, para calcular los gastos tributarios es necesario definir un impuesto de referencia. Los gastos tributarios serán todas aquellas regulaciones tributarias que se aparten de esa referencia.

A continuación se presentan dos recuadros en los que describen los impuestos de referencia utilizados para el Impuesto a la Renta, y el IVA, los conceptos utilizados, las definiciones de la norma y algunos ejemplos: ${ }^{16}$

${ }^{16}$ Ibid. Pp. 23 y 24. 


\section{Referencia para el Impuesto a la Renta}

\begin{tabular}{|c|c|c|}
\hline Concepto & Definición de Norma & Ejemplos de situaciones particulares \\
\hline Base Gravable & $\begin{array}{l}\text { El impuesto grava la renta global o comprehensiva, } \\
\text { entendida como el incremento de patrimonio más el } \\
\text { consumo del período (definición de Haig-Simons). Esta } \\
\text { definición es consistente con la de la propia Ley de } \\
\text { Impuesto a la Renta, que define como tal "los ingresos } \\
\text { que constituyan utilidades o beneficios que rinda una cosa } \\
\text { o actividad y todos los beneficios, utilidades, e } \\
\text { incrementos de patrimonio que se perciban o devenguen, } \\
\text { cualquiera sea su naturaleza, origen o denominación". }\end{array}$ & $\begin{array}{l}\text { No constituye GT: La deducción de costos y } \\
\text { gastos necesarios para producirla renta. } \\
\text { Constituyen GT: Los incentivos al ahorro } \\
\text { como el de artículo } 57 \text { bis. Las deducciones, } \\
\text { como las cotizaciones previsionales y de } \\
\text { salud. La aplicación del impuesto Global } \\
\text { Complementario sobre base realizada en } \\
\text { vez de base derengada. }\end{array}$ \\
\hline $\begin{array}{l}\text { Integración de } \\
\text { impuesto }\end{array}$ & $\begin{array}{l}\text { Los sujetos del impuesto son las personas naturales. Los } \\
\text { impuestos que pagan las personas jurídicas son sólo a } \\
\text { cuenta de los impuestos personales. }\end{array}$ & $\begin{array}{l}\text { No constituye GT: El crédito de primera } \\
\text { categoría, que evita la doble tributación de } \\
\text { las utilidades empresariales. }\end{array}$ \\
\hline \multirow[t]{2}{*}{ Tasas } & $\begin{array}{l}\text { La tasa del impuesto de Primera Categoría y las escal as de } \\
\text { tasas de los impuestos personales, en concordancia a su } \\
\text { vigencia respectiva. }\end{array}$ & $\begin{array}{l}\text { Constituye GT: La aplicación de cualquier } \\
\text { tasa diferente a las establecidas por la } \\
\text { norma. }\end{array}$ \\
\hline & $\begin{array}{l}\text { La tasa del impuesto único que afeda a las ganancias de } \\
\text { capital no habituales. }\end{array}$ & $\begin{array}{l}\text { No constituyen GT: El tramo exento de la } \\
\text { ecala de tasas del impuesto a las personas } \\
\text { naturales. La tasa de } 17 \% \text { a las ganancias de } \\
\text { capital no habituales. }\end{array}$ \\
\hline $\begin{array}{l}\text { Unidad de } \\
\text { Tributación }\end{array}$ & $\begin{array}{l}\text { Son las personas individuales, no existe la unidad familiar } \\
\text { tributaria. }\end{array}$ & \\
\hline $\begin{array}{l}\text { Período de } \\
\text { tributación }\end{array}$ & $\begin{array}{l}\text { Los períodos de tributación que establece la ley vigente. } \\
\text { Es decir, \& año calendario para los impuestos de Primera } \\
\text { Catøoría y Global Complementario, y el mes cal endario } \\
\text { para el impuesto único deSegunda Cat电oría. }\end{array}$ & \\
\hline $\begin{array}{l}\text { Ganancias de } \\
\text { capital }\end{array}$ & $\begin{array}{l}\text { En d caso de las ganancias de capital no habituales, se ha } \\
\text { considerado que a tratamiento normal para este tipo de } \\
\text { rentas etá representado por el Impuesto Único de } \\
\text { Primera Categoría. Para estos fectos, se consideran como } \\
\text { parte de la noma las actuales definiciones de } \\
\text { habitualidad contenidas en la Ley de la Renta, relativas a } \\
\text { frecuencia de operaciones y giro económico de los } \\
\text { contribuyentes. }\end{array}$ & $\begin{array}{l}\text { No constituye GT: La aplicación del } \\
\text { impuesto sobre base realizada en vez de } \\
\text { devengada. }\end{array}$ \\
\hline $\begin{array}{l}\text { Territorialidad de } \\
\text { la aplicación del } \\
\text { impuesto }\end{array}$ & $\begin{array}{l}\text { Los residentes pagan impuestos por su renta mundial, } \\
\text { mientras que los no residentes lo hacen solo por rentas de } \\
\text { fuente chilena. }\end{array}$ & $\begin{array}{l}\text { No constituye GT: El acreditamiento de } \\
\text { impuesto sobre la renta pagado o retenido } \\
\text { en otros países. }\end{array}$ \\
\hline $\begin{array}{l}\text { Pequeños } \\
\text { contribuyentes }\end{array}$ & $\begin{array}{l}\text { El impuesto debe contemplar regímenes simplificados } \\
\text { para pequeños contribuyentes, cuyo objetivo sea reducir } \\
\text { los costos de cumplimiento. Este es el caso de los } \\
\text { regímenes del artículo } 22 \text { de la ley de Impuesto a la Renta, } \\
\text { para pequeños mineros artesanales, suplementeros, } \\
\text { comerciantes, talleres artesanales y pescadores } \\
\text { artesanales, y el régimen de contabilidad simplificada para } \\
\text { contribuyentes que explotan bienes inmuebles. }\end{array}$ & $\begin{array}{l}\text { No constituyen GT: Los regímenes } \\
\text { simplificados del artículo } 22 \text {. } \\
\text { Constituyen GT: Los regímenes de renta } \\
\text { presuntay de los artículos } 14 \text { bis, } 14 \text { ter y } 14 \\
\text { quáter, pues su objedivo no es sólo } \\
\text { simplificar, sino además producir alivios } \\
\text { tributarios a quienes se acogen a ellos. }\end{array}$ \\
\hline
\end{tabular}

Pol. Con. (Edición núm. 7) Vol. 2, No 5, mayo 2017, pp. 869-918, ISSN: 2550 - 682X 


\section{Referencia para el IVA}

\begin{tabular}{|c|c|c|}
\hline Concepto & Definición de Norma & Ejemplos de situaciones particulares \\
\hline \multirow[t]{2}{*}{ Base gravable } & $\begin{array}{l}\text { El impuesto grava el consumo final, con una base } \\
\text { amplia. }\end{array}$ & $\begin{array}{l}\text { Constituye GT: Cual quier exención del impuesto } \\
\text { otorgada a bienes o servicios que representen } \\
\text { consumo. En particular, es GT la no sujeción } \\
\text { parcial de los bienes inmuebles. }\end{array}$ \\
\hline & & $\begin{array}{l}\text { No constituye GT: La exención a los arriendos de } \\
\text { vivienda, pues lo consistente con la base } \\
\text { consumo es gravar la venta de inmuebles y } \\
\text { eximir el arriendo o uso. }\end{array}$ \\
\hline $\begin{array}{l}\text { Principio(origen } \\
\text { odestino) }\end{array}$ & $\begin{array}{l}\text { Se aplica el principio de "destino". En } \\
\text { conseduencia, las importaciones etán afectas al } \\
\text { impuesto, mientras las exportaciones están } \\
\text { afectas a tasacero. }\end{array}$ & $\begin{array}{l}\text { No constituye GT: La devolución de IVA a } \\
\text { exportadores. }\end{array}$ \\
\hline Tasa & El impuesto se aplica con la tasa legal de $19 \%$. & $\begin{array}{l}\text { Constituye GT: La aplicación de cualquier tasa } \\
\text { inferior a la general. Es el caso de la venta de } \\
\text { viviendas, cuya tasa fectiva, por la aplicación } \\
\text { del crédito especial para empresas } \\
\text { constructoras, es de un } 6,65 \% \text {. }\end{array}$ \\
\hline $\begin{array}{l}\text { Devolución de } \\
\text { remanentes }\end{array}$ & $\begin{array}{l}\text { La devolu ción de remanentes de IVA, mantenidos } \\
\text { por más de seis meses y originado en compras de } \\
\text { activos fijos, se considera parte de la norma. }\end{array}$ & \\
\hline $\begin{array}{l}\text { Acuerdos } \\
\text { internacionales }\end{array}$ & $\begin{array}{l}\text { No se gravan las importaciones eftuadas por } \\
\text { representaciones diplomáticas, sujeto a } \\
\text { reciprocidad. Tampoco se gravan las } \\
\text { importaciones que no representan consumos, } \\
\text { tales como premios y trofeos, o que hayan pagado } \\
\text { IVA en Chile o el exterior, como \& equipaje de } \\
\text { viajeros. }\end{array}$ & \\
\hline
\end{tabular}

\section{Análisis del Gasto Tributario en Ecuador}

En Ecuador, el primer estudio sobre gastos tributarios fue realizado en 2003, de manera aislada. Desde 2007, el Servicio de Rentas Internas (SRI) viene publicando las estimaciones de aquéllos. Se utiliza el método de recaudación perdida, mediante un proceso muy preciso de análisis del marco jurídico, identificación de los gastos y cálculo. Las fuentes de información utilizadas son la encuesta sobre condiciones de vida y las declaraciones juradas. 
El método empleado para realizar la estimación del gasto tributario se denomina "pérdida de ingresos", entendido como el monto de ingresos tributarios del Estado que se reducen a causa de la existencia de una disposición particular que establece un incentivo.

El Gasto Tributario ha tenido una tendencia durante la última década variando del $4.3 \%$ al 5\%. En el año 2010, el gasto tributario en el Ecuador alcanzó USD 2,829.2 millones, este monto está compuesto por USD 1,446.3 millones de beneficios tributarios en Impuesto al Valor Agregado y USD 1382.9 millones de beneficios tributarios en Impuesto a la Renta, representado el 51.1\% y $48.8 \%$ del total de gasto entregado respectivamente

\section{Gastos Tributarios en principales impuestos del Ecuador}

\section{Gasto Tributario en el Impuesto al Valor Agregado}

La estimación del gasto tributario en la exoneración de IVA de bienes y servicios, se realizó con información de la Encuesta de Condiciones de Vida (ECV) año 2005-2006. Esta información comprende el consumo de 299 bienes y servicios para un conjunto de 55,666 individuos o un equivalente de 13,581 hogares (que en términos poblaciones corresponde a 13.278.358 individuos y 3.264.866 hogares). En el caso de la devolución y reintegro de IVA, se utilizó información del formulario de declaración 104; mientras que para el decreto 1232, se utilizó información de la Corporación Aduanera Ecuatoriana.

\section{Impuesto al Valor Agregado de Bienes}

El gasto tributario procedente del IVA causado en la adquisición de bienes se estimó para los siguientes numerales del artículo 55 de la LORTI: 
(1) Productos alimenticios de origen agrícola, avícola, pecuario, apícola, etc...,

(2) Leches en su estado natural y derivados,

(3) Pan, azúcar, fideos, harina, etc..,

(6) Medicamentos y drogas de uso humano, etc.

(7) Papel bond, periódicos, libros, revistas, etc.

El resto de numerales no se contemplaron debido a la falta de información.

Pese a que sólo se pudo estimar cinco de quince numerales vigentes en la LORTI, los numerales considerados concentran gran parte de los bienes que se comercian en la economía. El consumo de estos bienes se estimó tomando en cuenta:

Para los bienes alimenticios de origen agrícola, avícola, etc. (LORTI. Art. 55.

Numeral 1), los derivados lácteos (LORTI. Art. 55. Numeral 2) y los productos de harina, fideos, pan etc. (LORTI. Art. 55. Numeral 3), se utilizó la pregunta número 7 de la sección 8, numeral II de la ECV que corresponde al gasto en alimentos y bebidas no alcohólicas.

Para los bienes de salud se utilizó la información de la sección 8, numeral IV de la ECV correspondiente a gastos no alimenticios.

Para el gasto tributario en papel, libros, revistas, etc... (LORTI. Art. 55. Numeral 7), se utilizó la información de la sección 4 y la sección 8 parte A de la ECV, correspondiente a educación y gastos no alimenticios semanales, respectivamente.

Una vez calculado el consumo en cada uno de los bienes gravados con tarifa $0 \%$, se estimó el gasto tributario mediante la aplicación de la tasa de IVA (12\%) sobre el consumo exento y 
posteriormente se extrapoló este resultado hacia el Universo de hogares ecuatorianos utilizando el factor de expansión provisto por la ECV.

En este cálculo, la estimación del gasto tributario es ajustada por la fracción de crédito tributario generado en la transaccionalidad de cada bien en la economía (crédito estimado mediante la matriz insumo producto). Este ajuste se realiza para balancear la recaudación potencial estimada en la ECV con la recaudación efectiva que podría generar la Administración Tributaria.

Finalmente, se realiza un ajuste adicional para obtener el gasto tributario en valores del año 2010 utilizando la tasa de crecimiento de consumo nominal provisto por el Sistema de Cuentas Nacionales del Banco Central del Ecuador.

Bajo estos lineamientos, el gasto tributario en el Impuesto al Valor Agregado de bienes alcanza USD 759.79 millones en el año 2010, equivalente al 1.3\% del PIB o el $9.7 \%$ de la recaudación tributaria de dicho periodo. Los bienes que suministran mayor beneficio tributario constituyen los bienes alimenticios (art 55.1) con una transferencia indirecta de USD 401.26 millones. El resto de categorías causan un sacrificio entre USD 80 y USD 100 millones cada una, a excepción del papel, periódicos, revistas (art 55.7), los cuales tiene un gasto tributario de USD 61.25 millones.

\begin{tabular}{|c|c|c|c|c|}
\hline \multicolumn{5}{|c|}{ GASTO TRIBUTARIO IVA BIENES } \\
\hline Detalle & Millones USD & $\begin{array}{c}\text { \% Gasto Trib. } \\
\text { Total bienes }\end{array}$ & $\%$ Recaudación & $\% \mathrm{PIB}$ \\
\hline Bienes Alimenticios (art55.1) & 401.26 & $52.8 \%$ & $5.1 \%$ & $0.7 \%$ \\
\hline Leche y derivados (art55.2) & 99.64 & $13.1 \%$ & $1.3 \%$ & $0.2 \%$ \\
\hline Pan, Fideos, Azúcar, panela, etc..(art55.3) & 103.41 & $13.6 \%$ & $1.3 \%$ & $0.2 \%$ \\
\hline Medicamentos (art55. Num.6) & 94.22 & $12.4 \%$ & $1.2 \%$ & $0.2 \%$ \\
\hline Papel, periódicos, revistas, Libros, etc.. (art55.7) & 61.25 & $8.1 \%$ & $0.8 \%$ & $0.1 \%$ \\
\hline Gasto Tributario IVA Bienes & 759.79 & $100 \%$ & $9.7 \%$ & $1.3 \%$ \\
\hline
\end{tabular}


Por deciles de población beneficiaria, se tiene que en el $10 \%$ de los individuos de menores recursos posee un gasto tributario de USD 35.34 millones por consumo de bienes exentos de IVA, en tanto que el $10 \%$ de los individuos de mayores ingresos se beneficia por un monto equivalente a USD 148.25 millones por el consumo de dichos bienes como se puede apreciar en el siguiente gráfico.

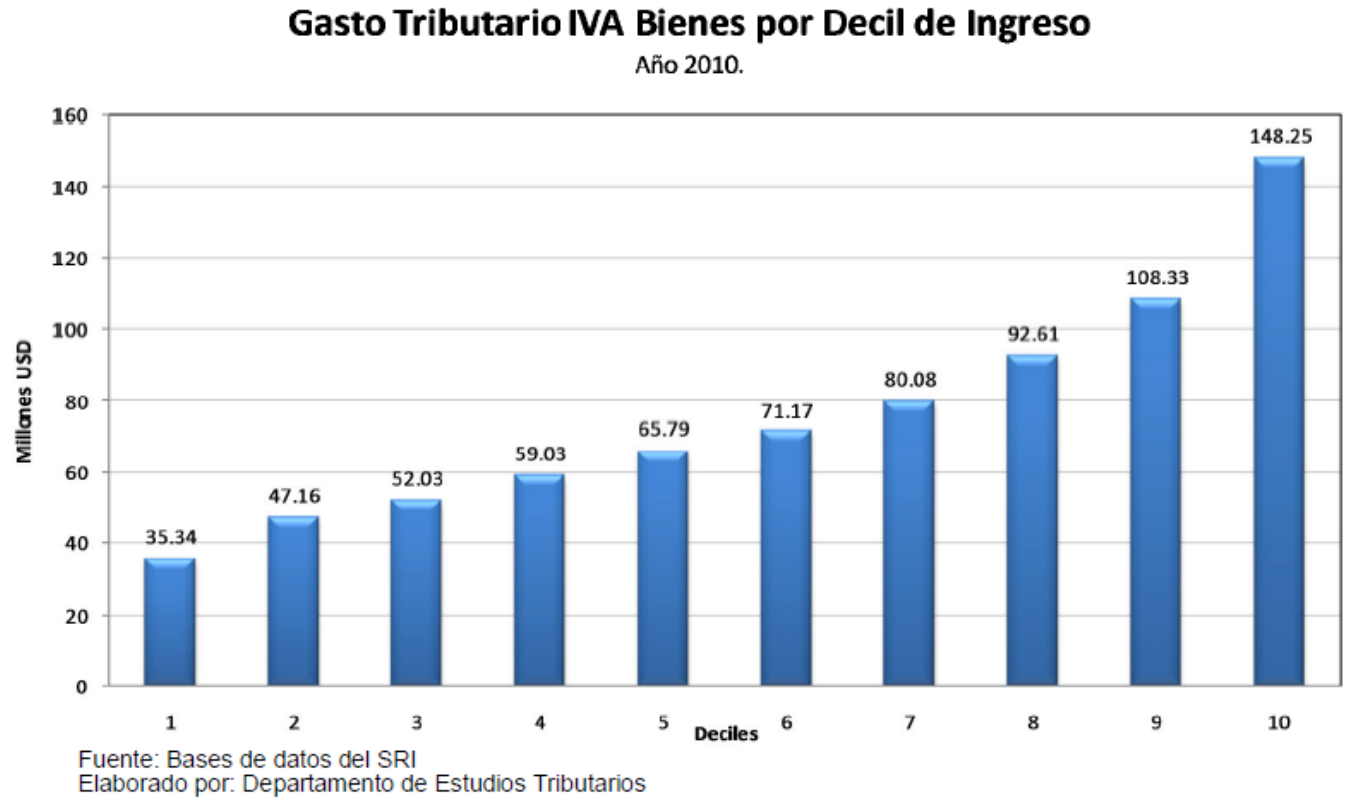

\section{Impuesto al Valor Agregado de Servicios ${ }^{17}$}

El gasto tributario procedente del IVA causado en la adquisición de servicios se cuantificó para los siguientes numerales del artículo 56 de la LORTI:

(1) Los de transporte nacional terrestre y acuático de pasajeros y carga;

(2) Los de salud, incluyendo los de medicina pre-pagada y los servicios de fabricación de medicamentos;

\footnotetext{
${ }^{17}$ Servicio de rentas internas- centro de estudios fiscales, 2013
} 
Cynthia M. Legarda-Arreaga; Grace E. Tello-Caicedo; Viviana E. Vera-Almache

(3) Los de alquiler o arrendamiento de inmuebles destinados, exclusivamente, para vivienda, en las condiciones que se establezca en el reglamento;

(4) Los servicios públicos de energía eléctrica, agua potable, etc.

(5) Los de educación en todos los niveles;

(8) Los de impresión de libros;

(9) Los funerarios;

(22) Los seguros y reaseguros de salud y vida individuales, en grupo, asistencia médica y accidentes personales, así como los obligatorios por accidentes de tránsito terrestres.

El resto de numerales no se contemplaron debido a la falta de información.

El proceso de estimación en las partidas citadas es más diverso y extenso que el empleado para el IVA en bienes, no obstante su cálculo es más directo a pesar de considerar solo 8 de 23 numerales. El consumo de estos servicios se determinó mediante los siguientes lineamientos:

Para los servicios de transporte, salud, ámbito religioso y funerario, financiero, turismo, peaje y lotería, se utilizó información del módulo de Otros Gastos no alimenticios, Sección 8 de la ECV.

Para los servicios de enseñanza, se utilizó información del módulo de educación, Sección 4 de la ECV.

Para los servicios arrendatarios y servicios básicos, se utilizó información del módulo de vivienda, Sección 1 de la ECV. 
Al igual que en la estimación del gasto del IVA en bienes, el consumo de servicios exentos sirvió como base para calcular el sacrificio fiscal mediante la aplicación de la tasa de IVA (12\%) sobre el gasto efectuado en dichos servicios. La estimación obtenida en esta fase fue ajustada por el factor de expansión de la ECV, la fracción del crédito tributario generado en la transaccionalidad de cada servicio en la economía y la tasa de crecimiento del consumo nominal al año 2010, tal como se realizó para el caso de bienes no gravados.

Con estos antecedentes metodológicos, la estimación del gasto tributario en la adquisición de servicios exentos totalizó USD 570.2 millones, es decir el 1\% del PIB o el 7.2\% de la recaudación tributaria. El sacrificio fiscal más representativo constituye las exoneraciones en el transporte y la educación, con un monto de USD 156.78 millones y USD 130.32 millones respectivamente.

\begin{tabular}{|c|c|c|c|c|}
\hline \multicolumn{5}{|c|}{ GASTO TRIBUTARIO IVA SERVICIOS } \\
\hline Detalle & Millones USD & $\begin{array}{c}\% \text { Gasto Trib. } \\
\text { Servicios }\end{array}$ & $\%$ Recaudación & $\% \mathrm{PIB}$ \\
\hline Transporte de pasajeros y carga (art56.1) & 156.78 & $27.5 \%$ & $2.0 \%$ & $0.3 \%$ \\
\hline Salud (art56.2) & 78.71 & $13.8 \%$ & $1.0 \%$ & $0.1 \%$ \\
\hline Alquiler y arrendamiento de inmuebles (art56.3) & 96.83 & $17.0 \%$ & $1.2 \%$ & $0.2 \%$ \\
\hline Servicios básicos (art56.4) & 59.62 & $10.5 \%$ & $0.8 \%$ & $0.1 \%$ \\
\hline Educación (art56.5) & 141.38 & $24.8 \%$ & $1.8 \%$ & $0.2 \%$ \\
\hline Los funera rios (art56.9) & 6.42 & $1.1 \%$ & $0.1 \%$ & $0.0 \%$ \\
\hline Financieros (art56.12) & 7.95 & $1.4 \%$ & $0.1 \%$ & $0.0 \%$ \\
\hline Peajes (art56.16) & 3.07 & $0.5 \%$ & $0.0 \%$ & $0.0 \%$ \\
\hline Lotería Junta de Beneficencia de Guayaquil (art56.17) & 14.14 & $2.5 \%$ & $0.2 \%$ & $0.0 \%$ \\
\hline Seguros y reaseguros de Salud y vida (art56.22) & 525 & $0.9 \%$ & $0.1 \%$ & $0.0 \%$ \\
\hline Gas to Tributario IVA Servicios & 570.2 & $100 \%$ & $7.2 \%$ & $1.0 \%$ \\
\hline
\end{tabular}

Fuente: Encuesta de Condiciones de Vida 2005-2006 Elaborado por: Departamento de Estudios Tributarios

Por tramos de renta, el decil más pobre posee un gasto tributario de USD 14.23 millones por consumo de servicios exentos de IVA, mientras que el decil mayores recursos posee un beneficio de 198.2 millones por dicho concepto. En otras palabras, el 10\% de la población más rica posee un beneficio por consumo de servicios no gravables equivalente a 14 veces el beneficio entregado al 10\% de la población más pobre. 
Cynthia M. Legarda-Arreaga; Grace E. Tello-Caicedo; Viviana E. Vera-Almache

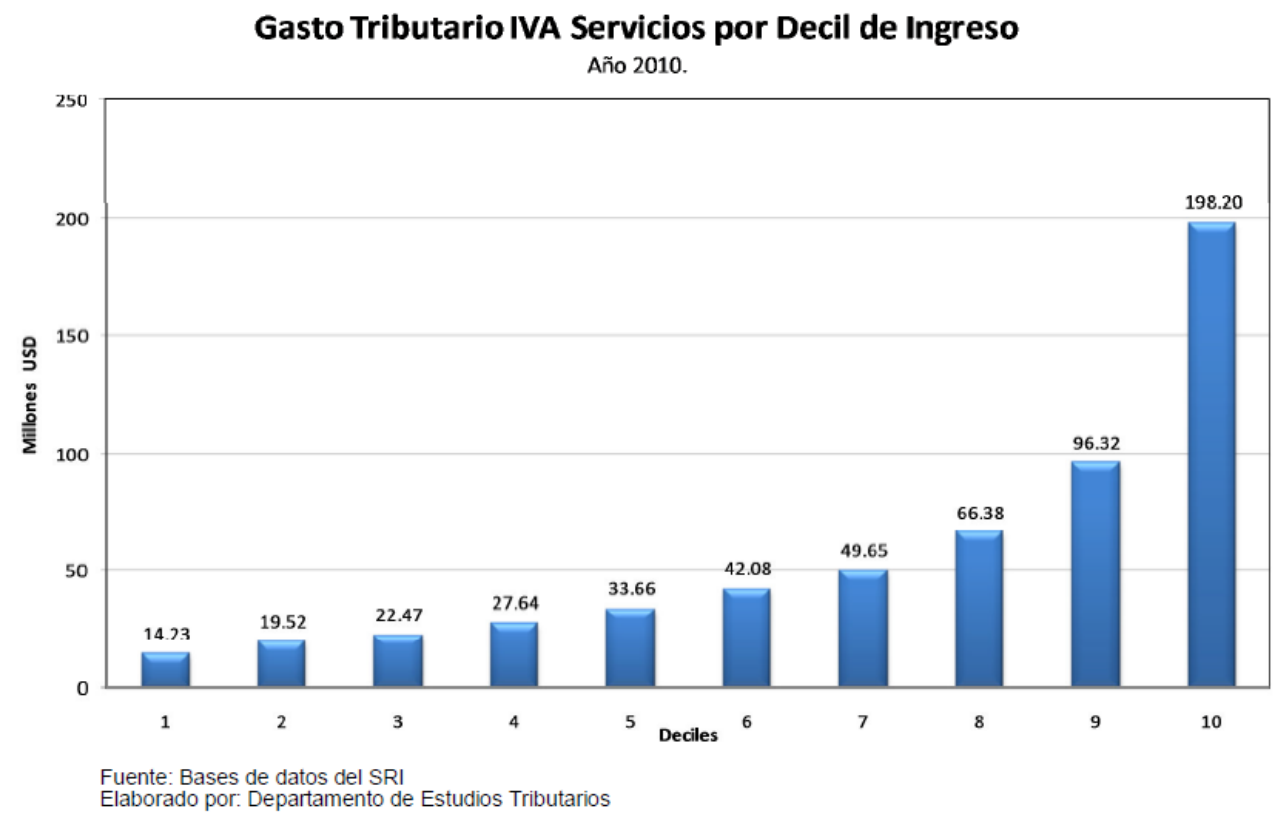

En el año 2006, el gasto tributario en el IVA representó $2.5 \%$ del PIB y $18.4 \%$ de la recaudación neta en el año 2010. Este sacrificio está compuesto por un $52.5 \%$ de exenciones en el consumo de bienes no gravados y un $39.4 \%$ de exenciones en el consumo de servicios no gravados.

\begin{tabular}{lcccc}
\hline \multicolumn{5}{c}{ GASTO TRIBUTARIO DEL IVA } \\
\hline \multicolumn{1}{c}{ Detalle } & Millones USD & $\begin{array}{c}\text { \% Gasto Tributario } \\
\text { \%otal }\end{array}$ & \%ecaudación & $\%$ PIB \\
\hline \hline Bienes & 759.8 & $52.5 \%$ & $9.7 \%$ & $1.3 \%$ \\
Servicios & 570.2 & $39.4 \%$ & $7.2 \%$ & $1.0 \%$ \\
Decreto 1232 & 66.0 & $4.6 \%$ & $0.8 \%$ & $0.1 \%$ \\
Devolucion y Reintegro & 50.4 & $3.5 \%$ & $0.6 \%$ & $0.1 \%$ \\
\hline \hline Total Gasto Tributario IVA & $\mathbf{1 , 4 4 6 . 3}$ & $\mathbf{1 0 0} \%$ & $\mathbf{1 8 . 4 \%}$ & $\mathbf{2 . 5 \%}$ \\
\hline
\end{tabular}

Fuentes: Encuesta de Condiciones de Vida 2005-2006, Base de Datos SRI Elaborado por: Departamento de Estudios Tributarios

\section{Gasto tributario en el Impuesto a la Renta}

El cual está compuesto por el impuesto a la renta de sociedades y el impuesto a la renta de personas naturales. 


\section{Gasto Tributario en el Impuesto a la Renta Sociedades}

El gasto tributario en el Impuesto a la Renta Sociedades comprende las siguientes exenciones y deducciones establecidas en la LORTI.

Artículo 9. Exenciones.

- Dividendos distribuidos por sociedades nacionales

- Rentas de Instituciones del Estado, Estados extranjeros y organismos internacionales, Instituciones sin fines de lucro, Institutos de educación superior y Cooperativas

Convenios de Doble Tributación:

- Ventas ocasionales de inmuebles, acciones o participaciones

Artículo 10. Deducciones:

- Amortización de pérdidas tributarias

- Deducción por nuevos empleados

- Depreciación acelerada

- Adicionalmente, se consideró también la reducción de 10 puntos porcentuales en el pago del impuesto a la renta por reinversión de utilidades según el artículo 37 de la LORTI.

No se consideraron como gasto tributario:

Los Contratos con el Estado por exploración y explotación de hidrocarburos 
Los Rendimientos distribuidos por fondos de inversión y otros

La Participación de los trabajadores en las utilidades

Las Indemnizaciones por seguros.

Debido a la restricción existente en la disponibilidad de información, se cuantificó el gasto tributario para los rubros de Reinversión de Utilidades, Deducciones por Leyes Especiales, Deducción por Nuevos Empleos, Depreciación Acelerada, Convenios de Doble Tributación, Amortización de pérdidas, Dividendos y la Renta de Instituciones sin Fines de Lucro. Esta estimación se realizó utilizando la información del formulario de declaración 101 del impuesto a la renta para el periodo fiscal $2010(\mathrm{SRI})$.

El gasto tributario en el Impuesto a la Renta Sociedades representó el $13.6 \%$ de la recaudación neta al año 2010. Con relación al PIB, esta pérdida representó el 1.9\%. La exoneración de dividendos distribuidos por sociedades generan el beneficio tributario más alto dentro del impuesto a la renta sociedades, con un gasto relativo del $60.6 \%$ sobre el total de sacrificio fiscal. En segundo lugar se tienen la exoneración por leyes especiales (dirigidas a sectores como explotación de minas y canteras, intermediación financiera, transporte y comunicaciones), con una pérdida equivalente al $9.9 \%$ gasto tributario total.

La exoneración a la renta de sociedades sin fines de lucro, ocupa también un lugar importante dentro del gasto tributario de sociedades con una participación del 9.6\%. 


\section{GASTO TRIBUTARIO EN IMPUESTO A LA RENTA DE SOCIEDADES}

\begin{tabular}{|c|c|c|c|c|}
\hline Detalle & Millones USD & $\begin{array}{c}\% \text { Gasto Tributario } \\
\text { Total } \\
\end{array}$ & \% Recaudación & $\%$ PIB \\
\hline Reinversión de utilidades & 56.7 & $5.3 \%$ & $0.7 \%$ & $0.1 \%$ \\
\hline Deducciones por Leyes especiales & 105.9 & $9.9 \%$ & $1.3 \%$ & $0.2 \%$ \\
\hline Deducción por nuevos empleos & 32.9 & $3.1 \%$ & $0.4 \%$ & $0.1 \%$ \\
\hline Depreciación acelerada & 16.3 & $1.5 \%$ & $0.2 \%$ & $0.0 \%$ \\
\hline Convenios de doble tributación & 81.8 & $7.7 \%$ & $1.0 \%$ & $0.1 \%$ \\
\hline Amortización de pérdidas & 23.9 & $2.2 \%$ & $0.3 \%$ & $0.0 \%$ \\
\hline Dividendos & 646.7 & $60.6 \%$ & $8.2 \%$ & $1.1 \%$ \\
\hline Otros (Consorcio Bloque 16) & 0.0 & $0.0 \%$ & p.0\% & $0.0 \%$ \\
\hline Sin fines de lucro & 102.7 & $9.6 \%$ & $1.3 \%$ & $0.2 \%$ \\
\hline Total Gasto Tributario Renta Sociedades & 1066.8 & 1.0 & $13.6 \%$ & $1.9 \%$ \\
\hline
\end{tabular}

Fuente: Bases de datos del SRI

Elaborado por: Departamento de Estudios Tributarios

Al analizar la distribución del gasto tributario por deciles de empresas, excluyendo dividendos, se observa una alta concentración en el último rango de ingresos, con cerca del $84.4 \%$ del total del beneficio entregado al 10\% de las sociedades de mayores ingresos, es decir USD 354.6 millones

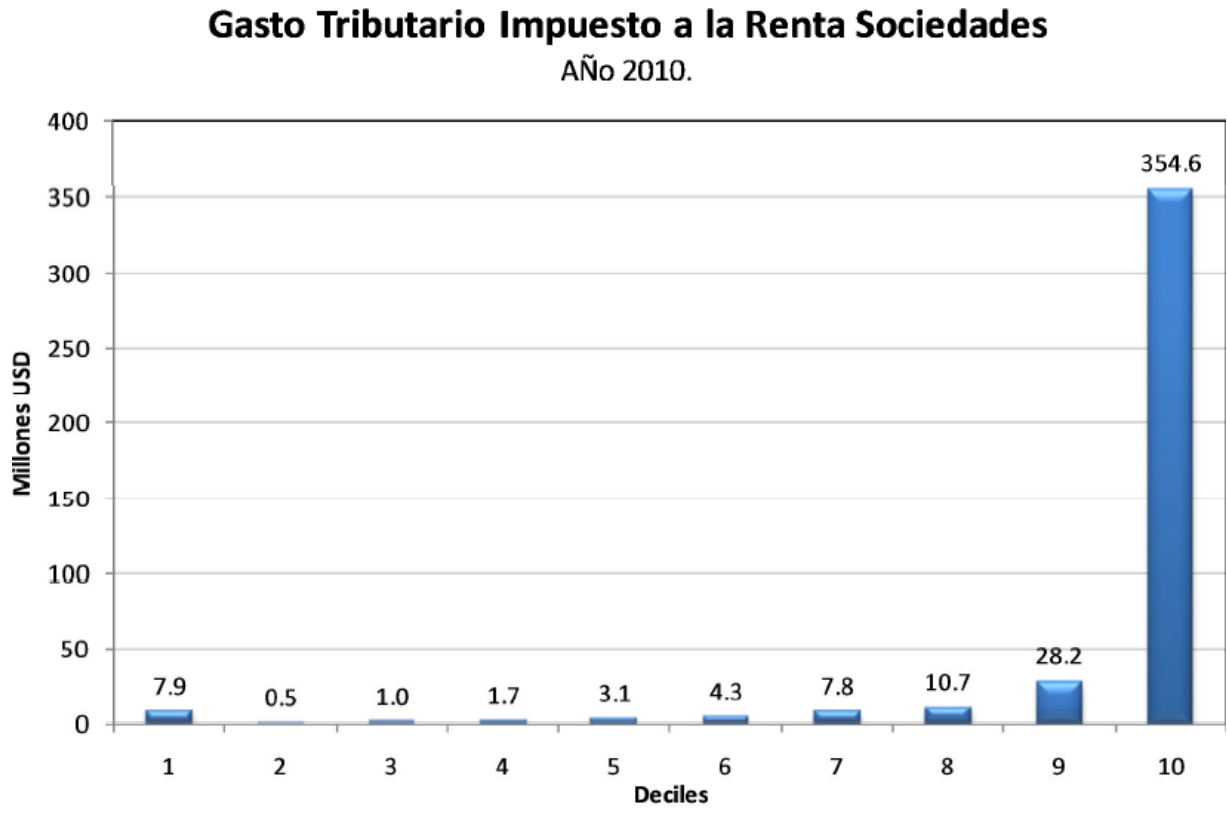


Cynthia M. Legarda-Arreaga; Grace E. Tello-Caicedo; Viviana E. Vera-Almache

\section{Gasto tributario en el Impuesto a la Renta de personas naturales}

El gasto tributario en el Impuesto a la Renta de Personas Naturales contempla las siguientes exenciones que se estipulan en el artículo 9 de la LORTI.

- Intereses por depósitos de ahorro

- Jubilaciones y pensiones

- Aporte personal del IESS

- Décimo tercera y décimo cuarta remuneraciones

- Premios de Loterías

- Rebajas a Discapacitados y Tercera Edad

- Enajenación ocasional de inmuebles, acciones o participaciones de personas naturales

El gasto tributario considera también las deducciones por gastos personales en salud, educación, alimentación, vestimenta y vivienda del Impuesto a la Renta de Personas Naturales, de acuerdo al artículo 73 de la Ley Reformatoria para la Equidad Tributaria.

No se consideraron como gasto tributario los Rendimientos distribuidos por fondos de inversión Debido a la disponibilidad de información, se estimaron los gastos correspondientes a la exoneración de rendimientos financieros, dividendos, aportaciones al IESS, sobresueldos, pensiones jubilares; la deducción por gastos personales; y las rebajas por discapacidad y tercera edad. 
La estimación del gasto tributario en el Impuesto a la Renta de Personas Naturales se realizó utilizando la información del formulario de declaración 101 del Impuesto a la Renta y del Anexo de Retención de Personas en Relación de Dependencia para el periodo fiscal 2010 (SRI).

El gasto tributario en el Impuesto a la Renta de Personas Naturales en el año 2010 representó el $0.6 \%$ del PIB y el $4 \%$ de la recaudación neta de ese período. El mayor beneficio suministrado constituye la deducción por gastos personales con una participación del 41.4\%.

Las aportaciones al IESS y la exoneración de sobresueldos representan también una parte importante del gasto tributario que realizan las personas naturales con una participación del 20.9\% y $17.3 \%$ respectivamente.

\begin{tabular}{|c|c|c|c|c|}
\hline \multicolumn{5}{|c|}{ GASTO TRIBUTARIO EN IMPUESTO A LA RENTA DE PERSONAS NATURALES } \\
\hline Detalle & Millones USD & $\begin{array}{c}\% \text { Gasto Tributario } \\
\text { Total } \\
\end{array}$ & \% Recaudación & $\%$ PIB \\
\hline Rendimientos Financieros & 21.4 & $\overline{6.8 \%}$ & $\overline{0.3 \%}$ & $0.0 \%$ \\
\hline Deducciones Aportes IESS & 66.0 & $20.9 \%$ & $0.8 \%$ & $0.1 \%$ \\
\hline Décimo tercera y décimo cuarta remuneraciones & 54.6 & $17.3 \%$ & $0.7 \%$ & $0.1 \%$ \\
\hline Gastos Personales & 130.8 & $41.4 \%$ & $1.7 \%$ & $0.2 \%$ \\
\hline Ingresos Exentos por pensiones jubilares & 3.8 & $1.2 \%$ & $0.0 \%$ & $0.0 \%$ \\
\hline Rebaja personas discapacitadas & 12.2 & $3.9 \%$ & $0.2 \%$ & $0.0 \%$ \\
\hline Rebaja personas tercera edad & 12.1 & $3.8 \%$ & $0.2 \%$ & $0.0 \%$ \\
\hline Dividendos & 15.0 & $4.8 \%$ & $0.2 \%$ & $0.0 \%$ \\
\hline Total Gasto Tributario Renta Personas Naturale & 316.1 & 1.0 & $4.0 \%$ & $0.6 \%$ \\
\hline
\end{tabular}

$\mathrm{Al}$ analizar la distribución del gasto tributario de personas en relación de dependencia (e.d. Deducciones Aportes IESS, Décimo tercer y décimo cuarta remuneración, Gastos Personales, Rebaja personas discapacitadas y tercera edad), se observa que el $80 \%$ de la población de menor renta acumula apenas el $0.65 \%$ del sacrificio total; es decir USD 1.7 millones. 
Cynthia M. Legarda-Arreaga; Grace E. Tello-Caicedo; Viviana E. Vera-Almache

\section{Gasto Tributario Impuesto a la Renta Personas Naturales}

Año 2010

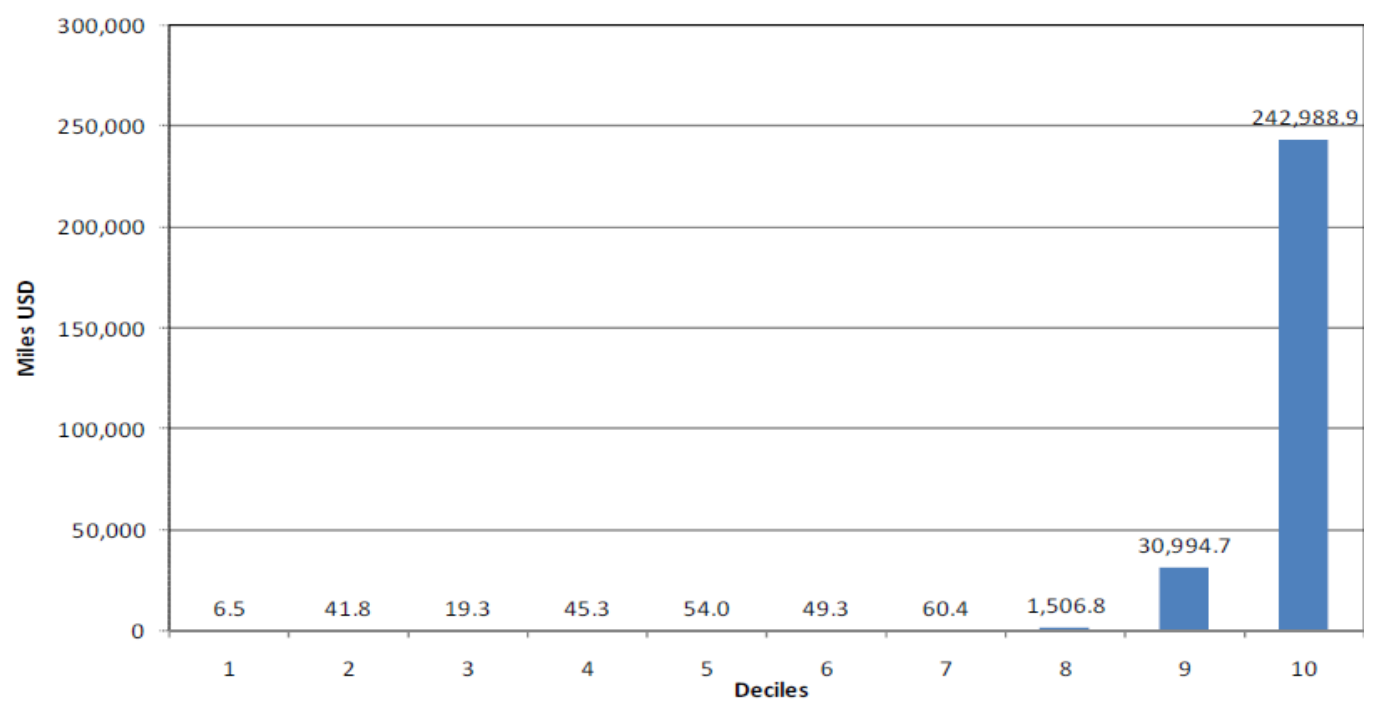

La evolución que ha presentado el Gasto Tributario ha tenido un variación constante entre el 4.5\% y 5\% en el año 2005 fue del 4.7\% del PIB y en 2007 del $4.5 \%$ siendo el $2.9 \%$ del Gasto Tributario por IVA y el restante gasto tributario del impuesto a la Renta del $1.6 \%$ el gasto tributario total del año 2010 ascendió al 5\% del PIB. El gasto tributario del IVA comprendió el 2.5\% del PIB, mientras que el gasto tributario en el Impuesto a la Renta constituyó el 2.4\%.

GASTO TRIBUTARIO TOTAL

\begin{tabular}{lcccc}
\hline \multicolumn{1}{c}{ Detalle } & Millones USD & $\begin{array}{c}\text { \% Gasto Tributario } \\
\text { Total }\end{array}$ & \%ecaudación & \multirow{2}{*}{$\%$ PIB } \\
\hline \hline Gasto Tributario del IVA & 1446.3 & $51.1 \%$ & $18.4 \%$ & $2.5 \%$ \\
Bienes (incluye decreto 1232 y devoluciones) & 876.2 & $31.0 \%$ & $11.1 \%$ & $1.5 \%$ \\
Servicios & 570.2 & $20.2 \%$ & $7.2 \%$ & $1.0 \%$ \\
Gasto Tributario de Renta & $1,382.9$ & $48.9 \%$ & $17.6 \%$ & $2.4 \%$ \\
Personas Naturales & 316.1 & $11.2 \%$ & $4.0 \%$ & $0.6 \%$ \\
Sociedades & $1,066.8$ & $37.7 \%$ & $13.6 \%$ & $1.9 \%$ \\
\hline \hline Total Gasto Tributario & $\mathbf{2 , 8 2 9 . 2}$ & $\mathbf{1 0 0 . 0} \%$ & $\mathbf{3 6 . 0} \%$ & $5.0 \%$ \\
\hline
\end{tabular}

Fuente: Encuesta de Condiciones de Vida 2005, Ministerio de Economía y Finanzas, Banco Central del Ecuador, Bases de datos del SRI

Elaborado por: Departamento de Estudios Tributarios

En el año 2010, el gasto tributario se dirige en mayor medida hacia los objetivos de redistribución del ingreso, con estrategias de mantener bajos los niveles de precios de algunos bienes 
básicos, así como mantener algunas exenciones para dotar de equidad y progresividad al sistema tributario

\begin{tabular}{|c|c|c|c|c|c|}
\hline \multicolumn{6}{|c|}{ GASTO TRIBUTARIO POR OBJETIVO DE POLITICA AÑO 2010} \\
\hline Objetivo General & Objetivo Específico & Millones USD & $\begin{array}{l}\text { \% Gasto } \\
\text { Tributario Total }\end{array}$ & \% Recaudación & \% PIB \\
\hline \multirow{8}{*}{ Asignación de Recursos } & Fomento a la Inversión & 305.4 & $10.8 \%$ & $3.9 \%$ & $0.5 \%$ \\
\hline & Leyes especiales & 105.9 & $3.7 \%$ & $1.3 \%$ & $0.2 \%$ \\
\hline & Reinversión de Utilidades & 56.7 & $2.0 \%$ & $0.7 \%$ & $0.1 \%$ \\
\hline & Depreciación acelerada & 16.3 & $0.6 \%$ & $0.2 \%$ & $0.0 \%$ \\
\hline & Amortización de pérdidas & 23.9 & $0.8 \%$ & $0.3 \%$ & $0.0 \%$ \\
\hline & Sin Fines de Lucro & 102.7 & $3.6 \%$ & $1.3 \%$ & $0.2 \%$ \\
\hline & Fomento al ahorro & 21.4 & $0.8 \%$ & $0.3 \%$ & $0.0 \%$ \\
\hline & Fomento al empleo & 32.9 & $1.2 \%$ & $0.4 \%$ & $0.1 \%$ \\
\hline Total Asignación de Recursos & & 359.7 & $12.7 \%$ & $4.6 \%$ & $0.6 \%$ \\
\hline \multirow[t]{4}{*}{ Provisión de bienes y servicios públicos } & Apoyo a la Educación & 202.6 & $7.2 \%$ & $2.6 \%$ & $0.4 \%$ \\
\hline & Apoyo a la Salud & 223.3 & $7.9 \%$ & $2.8 \%$ & $0.4 \%$ \\
\hline & Fomento a la infrestructura básica y Servicios públicos & 62.7 & $2.2 \%$ & $0.8 \%$ & $0.1 \%$ \\
\hline & Apoyo a la Vivienda & 96.8 & $3.4 \%$ & $1.2 \%$ & $0.2 \%$ \\
\hline Total Prov. Bienes y servicios públicos & & 585.5 & $20.7 \%$ & $7.4 \%$ & $1.0 \%$ \\
\hline \multicolumn{6}{|l|}{ Redistributivo } \\
\hline & Reducción de Precios a los Alimentos & 604.3 & $21.4 \%$ & $7.7 \%$ & $1.1 \%$ \\
\hline & Reducción de Precios al transporte & 156.8 & $5.5 \%$ & $2.0 \%$ & $0.3 \%$ \\
\hline & Equidad Redistributiva (gastos personales, rebajas a personas) & 279.6 & $9.9 \%$ & $3.6 \%$ & $0.5 \%$ \\
\hline Total Redistributivo & & $1,040.7$ & $36.8 \%$ & $13.2 \%$ & $1.8 \%$ \\
\hline \multicolumn{6}{|l|}{ Otros } \\
\hline & Convenios de Doble Tributación & 81.8 & $2.9 \%$ & $1.0 \%$ & $0.1 \%$ \\
\hline & Dividendos & 661.8 & $23.4 \%$ & $8.4 \%$ & $1.2 \%$ \\
\hline & Decreto 1232 & 66.0 & $2.3 \%$ & $0.8 \%$ & $0.1 \%$ \\
\hline & IVA varios (servicios funerarios, financieros, loterias y seguros) & 33.8 & $1.2 \%$ & $0.4 \%$ & $0.1 \%$ \\
\hline Total Otros & & 843.4 & $29.8 \%$ & $10.7 \%$ & $1.5 \%$ \\
\hline GASTO TRIBUTARIO TOTAL & 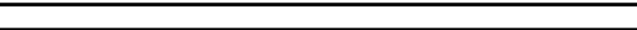 & $2,829.2$ & $100.0 \%$ & $36.0 \%$ & $5.0 \%$ \\
\hline
\end{tabular}

Según una estimación realizada por el Departamento de estudios tributarios para el año 2011 el Gasto Tributario total se situó en $4.3 \%$ con respecto a su PIB correspondiente al IVA del $2.9 \%$ y del impuesto a la renta de un $1.4 \%$.

$\%$ sobre el total

Total del gasto: $4.3 \%$ del PIB

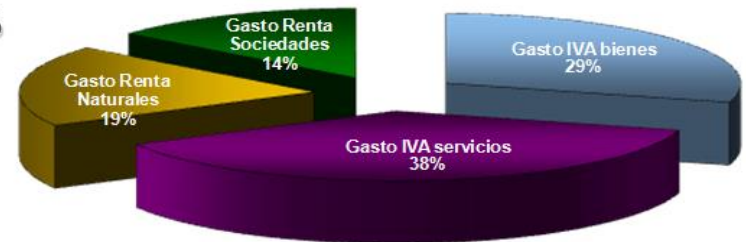

Exenciones, incentivos, reducciones, exoneraciones de impuestos, beneficios Tributarios (explícitos e implícitos en la normativa), implican una renuncia Fiscal significativa del Estado con la finalidad de alcanzar objetivos del Plan Nacional del Desarrollo. 
El Gráfico muestra la composición del Gasto Tributario total en Ecuador por tipo de impuestos donde el Gasto Tributario en el IVA de servicios es el que más aporta (38\%) estimación realizada para el año 2011.

Datos de Ecuador y Chile y su contextualización en América Latina y en la OCDE.

Análisis comparado y evaluación entre el Gasto Tributario en Chile y Ecuador

\section{Conclusiones}

Al comparar los sistemas tributarios de países determinamos que no existe uniformidad en la definición del Gasto Tributario ya que para algunos países existen varios conceptos que constituyen un Gasto Tributario indirecto y para otros no Por ejemplo para Ecuador y Chile los títulos de valores, cuya exención del IVA constituye un Gasto Tributario (con montos superiores a \$200 millones de dólares anuales) para otros países no constituye un Gasto Tributario. En cuanto al tipo de tributos analizados, los países se centran básicamente en el Impuesto al Valor Agregado (IVA) y en el Impuesto a la Renta (tanto de personas físicas como jurídicas) dado que son los de mayor poder recaudatorio.

Todo tipo de incentivo y exención de índole Tributario que se establezca debe ser monitoreado, evaluado y tenerse especial atención para que cumpla con los objetivos del Estado como son el fomento del empleo, el incremento de la productividad, cohesión social, y la atracción de inversión a largo plazo. Por ejemplo en el caso de empleo, si el incentivo fuera efectivo para generar empleo, no hay una focalización en los sectores estratégicos lo más conveniente sería derogar el incentivo tributario $\mathrm{y}$, en su reemplazo, destinar recursos equivalentes a aumentar las 
acciones de capacitación con financiamiento estatal, priorizando las demandas de formación de las empresas que pertenecen a los sectores definidos como estratégicos.

En Latinoamérica se ha utilizado en gran manera la herramienta de los gastos tributarios como política principal para la atracción de inversiones, este tema es de suma importancia sobre todo en gran medida tanto cuando se busca que la recaudación aumente, tener igualdad y simplificar los procedimientos y que exista más equidad, el cual nos ayuda a conocer la práctica del otorgamiento de incentivos y sus efectos.

La exigencia por parte de la comunidad internacional de que exista mayor transparencia en términos de política fiscal y el aumento del uso de las concesiones tributarias, dado con mayor relevancia en países en desarrollo que tratan de atraer inversiones, generando grandes expectativas y un gran interés al resto del mundo sobre todo de los gastos tributarios

Algunos estudios de otros países han demostrado que el Gasto Tributario no es influyente a la hora de atraer y fomentar la inversión, sino más bien un marco normativo bien estructurado y estabilidad jurídica, la infraestructura que facilite las actividades productivas, etc.

La OCDE Y el FMI lanzaron recomendaciones para una mayor transparencia fiscal sobre los Gastos Tributarios lo cual genero a divulgar la problemática e importancia de su estimación en varios países, aunque el gasto tributario sigue siendo en la actualidad un campo que aún no se ha abarcado en su totalidad, especialmente en los países en desarrollo, el cual aún no cuenta con metodologías analíticas sistemáticas que permitan analizar la dimensión de los gastos tributarios y poder realizar comparaciones y análisis entre países. 
Una diferencia importante de destacar entre las metodologías seguidas por los países analizados se refiere a la determinación del marco de referencia de cada tributo. Si bien la mayoría de los países se basa en la legislación tributaria para la determinación del marco de referencia, se encuentran diferentes criterios en cuanto a la consideración de algunos beneficios tributarios Así por ejemplo, hay países que consideran ciertas deducciones del impuesto a la renta dentro de la norma básica dado su carácter general mientras que otros las definen como beneficios destinados a ciertos grupos particulares por lo que forman parte de los gastos tributarios.

\section{Bibliografía.}

"Los presupuestos de gastos tributarios: conceptos y desafíos de implementación" Documento de Trabajo BID \# IDB-WP-131 consultado: 16-03-2013

Servicio de Rentas Internas (SRI) http://www.sri.gob.ec/web/10138/103 consultado: 16-03-2013

http://www.oecd.org Consultada: 27-04-2013

Wikipedia http://es. wikipedia.org consultada: 16-03-2013

La Carga Tributaria en el Ecuador Estudio de la Cámara de Industrias y Producción http://www.cip.org.ec/index.php?idSeccion=687

Ley de Régimen Tributario Interno consultado el 27/04/2013 http://www.rasonu.com.ec/index.php?option=com_remository \&Itemid=108\&func=fileinfo\&id=19\&1 ang=es

Centro Interamericano de Administraciones Tributarias - CIAT. (2006). La medición y el control de la erosión de las bases tributarias: los gastos tributarios y la evasión tributaria, Brasil, CIAT. 